\title{
Critical Analysis on the Structural and Magnetic Properties of Bulk and Nanocrystalline Cu-Fe-O
}

\author{
D. Paul Joseph, ${ }^{1,2}$ C. Venkateswaran, ${ }^{1}$ and R. Selva Vennila ${ }^{3,4}$ \\ ${ }^{1}$ Materials Science Centre, Department of Nuclear Physics, University of Madras, Guindy Campus, Chennai 600 025, India \\ ${ }^{2}$ Center for Condensed Matter Sciences, National Taiwan University, Taipei 10617, Taiwan \\ ${ }^{3}$ Center for Study of Matter at Extreme Conditions, Florida International University, Miami, FL 33199, USA \\ ${ }^{4}$ Lawrence Berkeley National Laboratory, Advanced Light Source, Berkeley, CA 94720, USA \\ Correspondence should be addressed to C. Venkateswaran, cvunom@hotmail.com
}

Received 1 November 2010; Accepted 16 December 2010

Academic Editor: Jacques Huot

Copyright @ 2010 D. Paul Joseph et al. This is an open access article distributed under the Creative Commons Attribution License, which permits unrestricted use, distribution, and reproduction in any medium, provided the original work is properly cited.

Nanocrystalline and bulk samples of "Fe"-doped $\mathrm{CuO}$ were prepared by coprecipitation and ceramic methods. Structural and compositional analyses were performed using X-ray diffraction, SEM, and EDAX. Traces of secondary phases such as CuFe $\mathrm{O}_{4}$, $\mathrm{Fe}_{3} \mathrm{O}_{4}$, and $\alpha-\mathrm{Fe}_{2} \mathrm{O}_{3}$ having peaks very close to that of the host $\mathrm{CuO}$ were identified from the Rietveld profile analysis and the SAED pattern of bulk and nanocrystalline $\mathrm{Cu}_{0.98} \mathrm{Fe}_{0.02} \mathrm{O}$ samples. Vibrating Sample Magnetometer (VSM) measurements show hysteresis at $300 \mathrm{~K}$ for all the samples. The ferrimagnetic Neel transition temperature $\left(T_{N}\right)$ was found to be around $465^{\circ} \mathrm{C}$ irrespective of the content of "Fe", which is close to the $T_{N}$ value of cubic $\mathrm{CuFe}_{2} \mathrm{O}_{4}$. High-pressure X-Ray diffraction studies were performed on $2 \%$ "Fe"-doped bulk $\mathrm{CuO}$ using synchrotron radiation. From the absence of any strong new peaks at high pressure, it is evident that the secondary phases if present could be less than the level of detection. $\mathrm{Cu}_{2} \mathrm{O}$, which is diamagnetic by nature, was also doped with $1 \%$ of "Fe" and was found to show paramagnetic behavior in contrast to the "Fe" doped CuO. Hence the possibility of intrinsic magnetization of "Fe"-doped $\mathrm{CuO}$ apart from the secondary phases is discussed based on the magnetization and charge state of "Fe" and the host into which it is substituted.

\section{Introduction}

Oxides such as $\mathrm{ZnO}, \mathrm{TiO}_{2}$, and $\mathrm{SnO}_{2}$ are currently explored as host materials for preparing Diluted Magnetic Semiconductors (DMSs) [1-7]. Among these, diamagnetic $\mathrm{ZnO}$ (n-type) doped with " $3 \mathrm{~d}$ " transition metal ions is presently explored in detail ([8-13] and references there in). Wide controversies exist in literature reports in explaining the observed results, and the role of preparation methods in deciding the property. $\mathrm{CuO}$ (Tenorite), a p-type semiconductor with a band gap of $1.2 \mathrm{eV}$, is an essential component in a variety of oxide superconductors and is also known for its catalytic and gas sensing properties [14-16]. $\mathrm{CuO}$ also being nontoxic and abundant, an attempt has been made to unravel its properties by doping with "Fe" and to find its potential for application in SPINTRONICS. "Cu" has three oxidation states, $\mathrm{Cu}^{+}, \mathrm{Cu}^{2+}$, and $\mathrm{Cu}^{3+}$, because of which both hole doping and electron doping are possible. "Fe" doping into
$\mathrm{CuO}$ has been attempted by researchers [17-21] by different preparation methods and was found to have no definite evidence for "Fe" replacing the "Cu" site in $\mathrm{CuO}$, as the two components are immiscible. Smith et al. have reported that introducing $\mathrm{Fe}_{2} \mathrm{O}_{3}$ into $\mathrm{CuO}$ by ceramic method is tough and phase segregation results above $0.3 \%$ of " $\mathrm{Fe}$ " in $\mathrm{CuO}$ [17]. Few reports exist on $\mathrm{CuO}$ doped with "Mn" [22] and "Fe" $[23,24]$ from DMS point of view. On the other hand, $\mathrm{Cu}_{2} \mathrm{O}$ (cuprite), also an eco-friendly p-type semiconductor with a direct band gap value of $2 \mathrm{eV}$ [25], is useful as an energy converter for solar cell applications [26] and as humidity and gas sensor material $[27,28]$. Reports also exist on magnetic properties of "Mn-", "Co-" and "Fe-" doped $\mathrm{Cu}_{2} \mathrm{O}[25,29$, 30]. Comparison of "Fe-doped $\mathrm{Cu}_{2} \mathrm{O}$ " with "Fe-doped $\mathrm{CuO}$ " may throw some light on the understanding of the intrinsic magnetic contribution of the later.

In this work, paramagnetic $\mathrm{CuO}$ (antiferromagnetic below $230 \mathrm{~K}$ ) doped with varying concentration of " $\mathrm{Fe}$ " 
was characterized in detail for its structural, compositional, and magnetization behavior by X-Ray diffraction (XRD), Rietveld analysis, Scanning electron microscopy (SEM), Energy Dispersive X-Ray analysis (EDAX), Transmission Electron Microscopy (TEM), Vibrating Sample Magnetometer (VSM), Thermogravimetric analyzer (TGA), Mössbauer spectroscopy, and XRD at high-pressures using synchrotron radiation. Presence of other related phases like $\mathrm{CuFe}_{2} \mathrm{O}_{4} / \mathrm{Fe}_{3} \mathrm{O}_{4}$ and $\mathrm{Fe}_{2} \mathrm{O}_{3}$, having coincidence with many of the major peak positions of $\mathrm{CuO}$, was not categorized before through the powder X-ray diffraction in detail. Their presence is only discussed based on the Mössbauer spectra [20, 21, 23]. We performed a detailed powder Xray diffraction study using Rietveld refinement procedure and cross checked the presence of $\mathrm{CuFe}_{2} \mathrm{O}_{4}$ from the Neel temperature $\left(T_{N}\right)$ measurement using a TGA with a small applied field. High-pressure studies were carried out to identify the presence of any possible secondary phases. We have also discussed the effect of secondary phases in $\mathrm{CuO}$ and also compared with $1 \%$ and $2 \%$ "Fe"-doped $\mathrm{Cu}_{2} \mathrm{O}$. The possibility of intrinsic magnetization of "Fe"-doped $\mathrm{CuO}$ [24] apart from the ferrite phases is discussed based on the magnetization measurements and the charge state of "Fe" in the host into which it is substituted.

\section{Sample Preparation and Experimental Details}

Nanocrystalline samples of $\mathrm{Cu}_{(1-x)} \mathrm{Fe}_{x} \mathrm{O}(x=0.01,0.02$, $0.03,0.04$, and 0.05 ) were prepared from the stoichiometric solutions of copper nitrate and iron nitrate in deionized water by coprecipitation method after refluxing for 20 hour, 30 hour, 40 hour and 50 hour. Precipitation was done using aqueous $\mathrm{NH}_{4} \mathrm{OH}$ and peptized with deionized water to remove by-products. The filtrates were then dried, powdered and annealed at various temperatures. Nanocrystalline $\mathrm{CuFe}_{2} \mathrm{O}_{4}$ and bulk $\mathrm{Cu}_{(1-x)} \mathrm{Fe}_{x} \mathrm{O}(x=0.01,0.02,0.03$, $0.04,0.05$ and 0.07 ) were also prepared for comparing the properties. For the preparation of bulk samples, stoichiometric mixtures of oxides were ground in isopropyl alcohol medium, pelleted and sintered at $900^{\circ} \mathrm{C} / 12 \mathrm{~h}$ in air.

Chemical coprecipitation method with subsequent reduction of the precipitates was employed to prepare the samples of $\mathrm{Cu}_{2} \mathrm{O}: \mathrm{Fe}(1 \%$ and $2 \%)$. Copper sulphate and ferric nitrate solutions for the required stoichiometry were prepared with de-ionized water. Aqueous $\mathrm{NH}_{4} \mathrm{OH}(0.15 \mathrm{M})$ solution was added to the solution with constant stirring. After stirring for 15 minutes, $1.2 \mathrm{M} \mathrm{NaOH}$ solution was added in drops to the solution, to form light green precipitates. Further, $2 \mathrm{~mL}$ of $10 \mathrm{M} \mathrm{N}_{2} \mathrm{H}_{4}$ was added, continued by 5 hour stirring to reduce the sample to form " $\mathrm{Fe}$ "-doped $\mathrm{Cu}_{2} \mathrm{O}$ [30] and $\mathrm{Cu}_{2} \mathrm{O}[31]$.

2.1. X-Ray Diffraction Results. Nanocrystalline $\mathrm{Cu}_{0.95} \mathrm{Fe}_{0.05} \mathrm{O}$ samples were annealed at $500^{\circ} \mathrm{C}, 700^{\circ} \mathrm{C}, 900^{\circ} \mathrm{C} / 2 \mathrm{~h}$, and also at $900^{\circ} \mathrm{C} / 12 \mathrm{~h}$ in air. X-Ray diffraction measurements were done using $\mathrm{CuK}_{\alpha}$ radiation in the range $10^{\circ}-80^{\circ}$ with a step

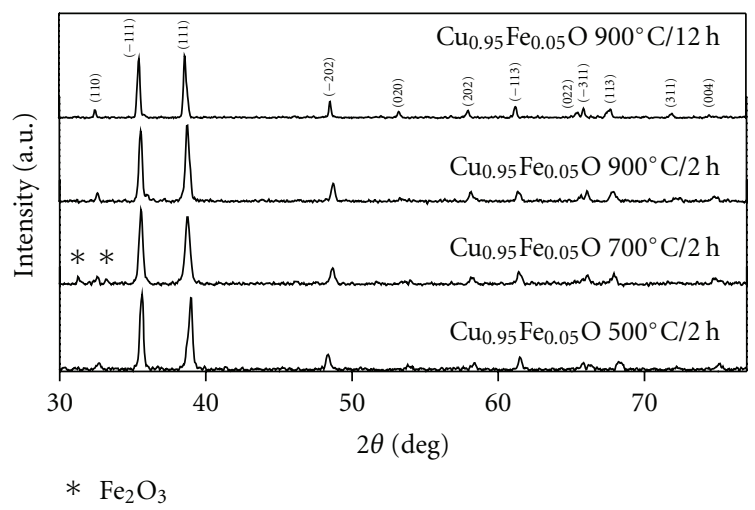

FIGURE 1: XRD patterns of 50-hour refluxed nanocrystalline $\mathrm{Cu}_{0.95} \mathrm{Fe}_{0.05} \mathrm{O}$ annealed at different temperatures.

size of $0.04^{\circ}$ (Rich Seifert 2000, transmission geometry). All the peaks could be indexed to the monoclinic structure of $\mathrm{CuO}$. Representative XRD patterns of 50 hours refluxed $\mathrm{Cu}_{0.95} \mathrm{Fe}_{0.05} \mathrm{O}$ sample annealed at different temperatures are shown in Figure 1. The samples annealed at $700^{\circ} \mathrm{C} / 2 \mathrm{~h}$ presented $\mathrm{Fe}_{2} \mathrm{O}_{3}$ peaks of small intensity around $31^{\circ}$ and $33^{\circ}$. However, after annealing the samples at $900^{\circ} \mathrm{C}$ those peaks vanished and only lines of $\mathrm{CuO}$ phase were evident. Hence all the nanocrystalline $\mathrm{Cu}_{(1-x)} \mathrm{Fe}_{x} \mathrm{O}(x=0.01,0.02$, $0.03,0.04$, and 0.05) samples and $\mathrm{Cu}_{0.95} \mathrm{Fe}_{0.05} \mathrm{O}$ samples refluxed for 20 hour, 30 hour, 40 hour, and 50 hour were annealed at $900^{\circ} \mathrm{C} / 2 \mathrm{~h}$. Based on these results the samples were first considered as single phase and the magnetization and other measurements were performed. However, most of the reflections of monoclinic $\mathrm{CuO}$ (Monoclinic, JCPDS \# 652309) match with those of ferrimagnetic $\mathrm{CuFe}_{2} \mathrm{O}_{4}$ (Cubic, JCPDS file No. 77-0010), $\mathrm{Fe}_{3} \mathrm{O}_{4}$ (Cubic, JCPDS file No. 851436), and paramagnetic $\mathrm{Fe}_{2} \mathrm{O}_{3}$ (Rhombohedral, JCPDS file No. 80-2377). Some of the peaks of $\mathrm{CuFe}_{2} \mathrm{O}_{4} / \mathrm{Fe}_{3} \mathrm{O}_{4}$ and $\mathrm{Fe}_{2} \mathrm{O}_{3}$ having same hkl planes and position very close to that of the host $\mathrm{CuO}$ are tabulated in Table 1. This overlap of reflections presented the problem of identifying hidden impurity phases.

2.2. Rietveld Analysis. XRD measurement with a step size of $0.01^{\circ}$ with an exposure time of 8 seconds was performed on the as-mixed powders of $\mathrm{CuO}: \mathrm{Fe}_{2} \mathrm{O}_{3}(2 \%)$ and on the same mixtures but sintered at $900^{\circ} \mathrm{C} / 12 \mathrm{~h}$ in air. Interestingly, from the close scan XRD spectrum, the subtle merged peaks belonging to the ferrimagnetic cubic $\mathrm{CuFe}_{2} \mathrm{O}_{4}$ phase were identified. The full-scale view of the close scan XRD pattern of as-mixed $\mathrm{CuO}: \mathrm{Fe}_{2} \mathrm{O}_{3}(2 \%)$ presents peaks of $\mathrm{CuO}$ and $\mathrm{Fe}_{2} \mathrm{O}_{3}$. On sintering at $900^{\circ} \mathrm{C} / 12 \mathrm{~h}$ in air, all the lines of $\mathrm{Fe}_{2} \mathrm{O}_{3}$ vanished indicating the substitution of "Fe" into the copper site and the $\mathrm{CuO}$ main phase lines were alone evident. The phase quantification by Rietveld refinement using a program called MAUD [32], which combines the Rietveld method and a Fourier transform analysis, also indicated the existence of $0.2 \%$ of $\mathrm{CuFe}_{2} \mathrm{O}_{4}$ in the samples. The results of refinement are given in Table 2 . The observed pattern matches with that 
TABle 1: Peak position, intensity, and hkl values of possible secondary phases in Fe-doped CuO from XRD pattern.

\begin{tabular}{|c|c|c|c|c|c|c|c|c|c|}
\hline \multicolumn{2}{|c|}{$\mathrm{CuO}$} & \multicolumn{3}{|c|}{$\mathrm{CuFe}_{2} \mathrm{O}_{4}$} & \multicolumn{3}{|c|}{$\mathrm{Fe}_{3} \mathrm{O}_{4}$} & \multicolumn{2}{|c|}{$\mathrm{Fe}_{2} \mathrm{O}_{3}$} \\
\hline $2 \theta$ & Int & $2 \theta$ & Int & hkl & $2 \theta$ & Int & $\mathrm{hkl}$ & $2 \theta$ & Int \\
\hline 35.663 & 999 & 35.543 & 999 & 311 & 35.443 & 999 & 311 & 35.631 & 719 \\
\hline 46.401 & 14 & 47.299 & 009 & 331 & 47.162 & 007 & 331 & - & - \\
\hline 53.615 & 71 & 53.596 & 076 & 422 & 53.438 & 088 & 422 & 54.066 & 427 \\
\hline 56.863 & 06 & 57.135 & 259 & 511 & 56.964 & 281 & 511 & - & - \\
\hline 65.989 & 96 & 65.974 & 010 & 531 & 65.770 & 009 & 531 & 66.030 & 003 \\
\hline 75.235 & 35 & 75.244 & 027 & 622 & 75.002 & 030 & 622 & 75.456 & 059 \\
\hline 87.103 & 09 & 87.051 & 022 & 642 & 86.754 & 030 & 642 & - & - \\
\hline 90.064 & 15 & 89.964 & 081 & 731 & 89.650 & 102 & 731 & - & - \\
\hline
\end{tabular}

TABLE 2: Structural and compositional parameters of bulk as-mixed and sintered $\mathrm{CuO}: \mathrm{Fe}_{2} \mathrm{O}_{3}(2 \%)$ along with possible secondary phases from Rietveld Refinement of the X-ray data.

\begin{tabular}{|c|c|c|}
\hline \multirow[b]{2}{*}{ Phase } & \multicolumn{2}{|c|}{$\mathrm{CuO}: \mathrm{Fe}_{2} \mathrm{O}_{3}(2 \%)$} \\
\hline & As-mixed & $\begin{array}{l}\text { Sintered } \\
\left(900^{\circ} \mathrm{C} / 12 \mathrm{~h} \text { in air }\right)\end{array}$ \\
\hline$\overline{\mathrm{CuO}}$ & $a=4.694 \AA$ & $a=4.688 \AA$ \\
\hline \multirow{4}{*}{$\begin{array}{l}\text { Monoclinic } \\
(\mathrm{C} 2 / \mathrm{C})\end{array}$} & $b=3.433 \AA$ & $b=3.425 \AA$ \\
\hline & $c=5.144 \AA$ & $c=5.134 \AA$ \\
\hline & $\beta=99.43$ & $\beta=99.47$ \\
\hline & $\%$ of $\mathrm{CuO}=97.3 \%$ & $\%$ of $\mathrm{CuO}=99.8 \%$ \\
\hline$\overline{\mathrm{Fe}_{2} \mathrm{O}_{3}}$ & $a=5.034 \AA$ & 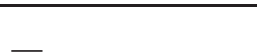 \\
\hline \multirow{2}{*}{ Trigonal (R $\overline{3} \mathrm{C})$} & $c=13.802 \AA$ & \\
\hline & $\%$ of $\mathrm{Fe}_{2} \mathrm{O}_{3}=2.7 \%$ & \\
\hline $\mathrm{CuFe}_{2} \mathrm{O}_{4}$ & \multirow[t]{2}{*}{-} & $a=8.388 \AA$ \\
\hline Cubic (Fd $\overline{3} \mathrm{~m})$ & & $\begin{array}{l}\% \text { of } \\
\mathrm{CuFe}_{2} \mathrm{O}_{4}=0.2 \%\end{array}$ \\
\hline Overall $R$ factor & 8.038 & 1.760 \\
\hline $\begin{array}{l}\text { Overall } \\
\text { goodness of the } \\
\text { fit }(\sigma)\end{array}$ & 1.223 & 2.643 \\
\hline
\end{tabular}

of the monoclinic $\mathrm{CuO}$ phase there by indicating that the dopants were incorporated into the $\mathrm{CuO}$ matrix. The profile analysis and the difference pattern of as-mixed and sintered $\mathrm{CuO}: \mathrm{Fe}_{2} \mathrm{O}_{3}(2 \%)$ along with the vertical lines indicating the peak position of the $\mathrm{CuO}$ main phase and the $\mathrm{CuFe}_{2} \mathrm{O}_{4}$ impurity phase are shown in Figure 2. The square root of intensity is plotted so as to clearly depict the closeness of the peaks and also to show the presence of less intense impurity peaks.

2.3. SEM and EDAX Results. SEM measurements were performed on nanocrystalline $\mathrm{Cu}_{0.95} \mathrm{Fe}_{0.05} \mathrm{O}$ samples obtained after refluxing for 40 hour. The image corresponding to the as-prepared sample shows particles with rod-like and disc-shaped morphologies (Figure 3), and their thickness increases when annealed at $500^{\circ} \mathrm{C} / 2 \mathrm{~h}$ in air; however it was less than a micrometer. The thickness and length of the rod shaped particles alone were measured. A Gaussian fit was given and the average value of thickness was found to be $78 \mathrm{~nm}$ with an average length of $0.366 \mu \mathrm{m}$. As the temperature was raised to $700^{\circ} \mathrm{C} / 2 \mathrm{~h}$, the rod-like morphology vanishes and the particles grow in size. At $900^{\circ} \mathrm{C} / 2 \mathrm{~h}$ the particle morphology transforms to platelets due to temperature-induced agglomeration and growth (not shown here). Compositional analysis by EDAX confirmed the desired composition of "Fe" in the entire batch of samples (not presented here). The nominal variation in composition is due to the random alloying of the magnetic dopants.

The observation of two different particle morphologies, rod-like and platelet-like may be an indication of existence of two different phases. Rod- and platelet-like morphology may be the undoped $\mathrm{CuO}$ and $\mathrm{CuFe}_{2} \mathrm{O}_{4}$ phases, respectively. This argument is supported by the magnetization results which are discussed in the following sections. The samples annealed at lower temperature are found to have paramagnetic component [24] without saturation superimposed with the hysteresis behavior (bottom inset of Figure 10). This is because the temperature is not sufficient for the $\mathrm{CuFe}_{2} \mathrm{O}_{4}$ to crystallize out. Hence, after annealing at $900^{\circ} \mathrm{C}$ in air, the magnetization curve becomes smooth and the corresponding SEM micrograph presented only platelet-like particles (not presented here).

2.4. TEM Results. The selected area electron diffraction (SAED) on bulk $\mathrm{Cu}_{0.95} \mathrm{Fe}_{0.05} \mathrm{O}\left(900^{\circ} \mathrm{C} / 12 \mathrm{~h}\right)$ was performed by selecting samples from three different locations in a JEOL EX2000. The TEM micrograph and SAED pattern (inset) is shown in Figure 4. All the $d_{\mathrm{hkl}}$ values corresponding to the streaky spot pattern were calculated and compared with the $d_{\text {hkl }}$ values of the host $\mathrm{CuO}$ (JCPDS 65-2309), and possible secondary phases such as cubic $\mathrm{CuFe}_{2} \mathrm{O}_{4}$ (JCPDS 77-0010), cubic $\mathrm{Fe}_{3} \mathrm{O}_{4}$ (JCPDS 85-1436), and rhombohedral $\alpha-\mathrm{Fe}_{2} \mathrm{O}_{3}$ (JCPDS 80-2377). The $d_{\mathrm{hkl}}$ and corresponding hkl values of $\mathrm{Cu}_{0.95} \mathrm{Fe}_{0.05} \mathrm{O}$ and possible secondary phases are listed in Table 3. This is also confirmed from SAED patterns for samples taken from three different locations (not shown here). From the above result, it is seen that $\mathrm{Cu}_{0.95} \mathrm{Fe}_{0.05} \mathrm{O}$ sample has the secondary phases of $\mathrm{CuFe}_{2} \mathrm{O}_{4} / \mathrm{Fe}_{3} \mathrm{O}_{4}$ and $\alpha-\mathrm{Fe}_{2} \mathrm{O}_{3}$. 


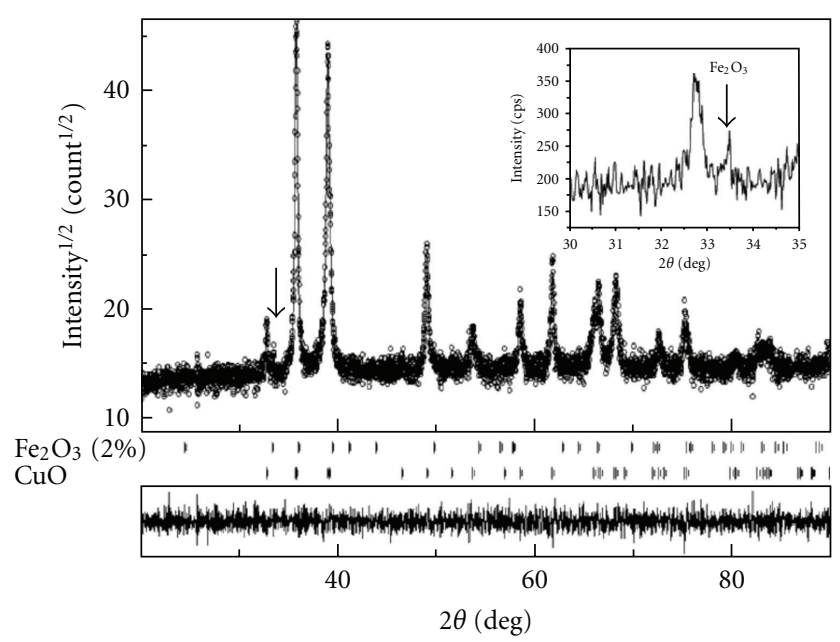

(a)

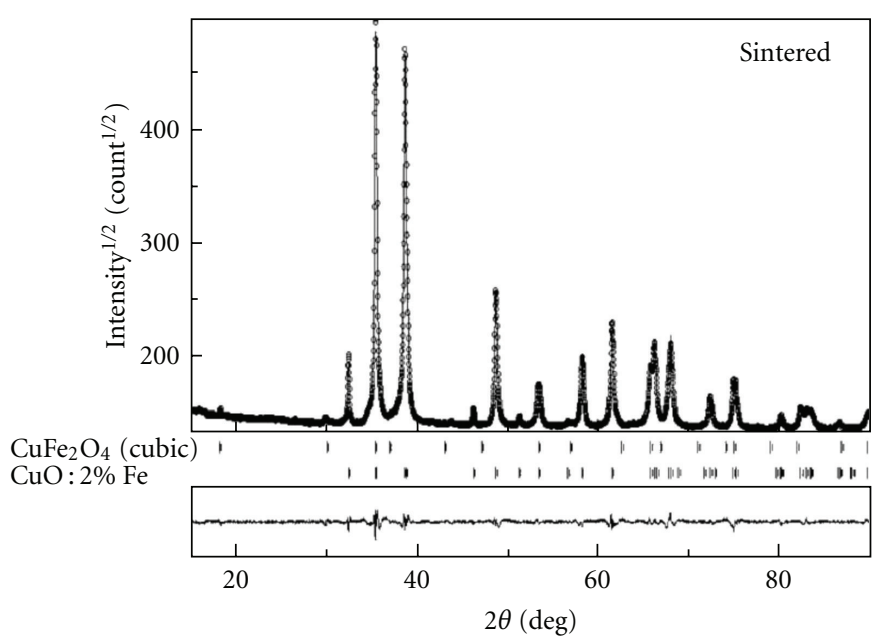

(b)

FIgURE 2: Rietveld refinement of the XRD patterns of as-mixed $\mathrm{CuO}: \mathrm{Fe}_{2} \mathrm{O}_{3}(2 \%)$ (a) and that sintered at $900^{\circ} \mathrm{C} / 12 \mathrm{~h}$ in air (b). The open circles indicate the observed pattern, and the overlying continuous line represents the calculated pattern. The vertical lines indicate the peak position of the respective phases. The bottom continuous line of each pattern represents the difference between the observed and calculated (Obs-Cal) patterns.

TABLE 3: $d_{\mathrm{hkl}}$ and hkl values of bulk $\mathrm{Cu}_{0.95} \mathrm{Fe}_{0.05} \mathrm{O}$ shown in comparison with possible secondary phases to indicate the closeness of the $d_{\mathrm{hkl}}$ values.

\begin{tabular}{|c|c|c|c|c|c|c|c|c|}
\hline \multirow{2}{*}{$\begin{array}{l}d_{\mathrm{hkl}}(\AA) \text { of } \\
\mathrm{Cu}_{0.95} \mathrm{Fe}_{0.05} \mathrm{O} \\
\text { from SAED }\end{array}$} & \multicolumn{2}{|c|}{$\begin{array}{l}\text { Monoclinic } \mathrm{CuO} \\
\text { JCPDS 65-2309 }\end{array}$} & \multicolumn{2}{|c|}{$\begin{array}{l}\text { Cubic } \mathrm{CuFe}_{2} \mathrm{O}_{4} \\
\text { JCPDS 77-0010 }\end{array}$} & \multicolumn{2}{|c|}{$\begin{array}{c}\text { Cubic } \mathrm{Fe}_{3} \mathrm{O}_{4} \\
\text { JCPDS 85-1436 }\end{array}$} & \multicolumn{2}{|c|}{$\begin{array}{c}\text { Rhombohedral } \\
\alpha-\mathrm{Fe}_{2} \mathrm{O}_{3} \text { JCPDS 80-2377 }\end{array}$} \\
\hline & $d_{\mathrm{hkl}}(\AA)$ & $\mathrm{hkl}$ & $d_{\mathrm{hkl}}(\AA)$ & $\mathrm{hkl}$ & $d_{\mathrm{hkl}}(\AA)$ & $\mathrm{hkl}$ & $d_{\mathrm{hkl}}(\AA)$ & hkl \\
\hline 2.823 & 2.742 & 110 & 2.959 & 220 & 2.967 & 220 & 2.699 & $104^{*}$ \\
\hline 2.430 & 2.515 & $-111^{*}$ & 2.523 & $311^{*}$ & 2.530 & $311^{*}$ & 2.517 & 110 \\
\hline 2.240 & 2.315 & 111 & - & - & - & - & 2.206 & 113 \\
\hline 1.929 & 1.955 & -112 & 1.920 & 331 & 1.925 & 331 & 1.841 & 024 \\
\hline 1.666 & 1.708 & 020 & 1.610 & 511 & 1.615 & 511 & 1.694 & 116 \\
\hline 1.485 & 1.575 & 202 & 1.479 & 440 & 1.483 & 440 & 1.486 & 214 \\
\hline 1.333 & 1.371 & 220 & 1.323 & 620 & 1.325 & 620 & 1.349 & 208 \\
\hline 1.220 & 1.298 & 311 & 1.208 & 444 & 1.211 & 444 & 1.258 & 220 \\
\hline 1.109 & 1.117 & -402 & 1.118 & 642 & 1.121 & 642 & 1.103 & 226 \\
\hline 1.015 & 1.014 & 223 & 1.089 & 731 & 1.092 & 731 & - & - \\
\hline 0.944 & 0.941 & -133 & - & - & - & - & - & - \\
\hline 0.909 & 0.915 & -331 & - & - & - & - & - & - \\
\hline 0.887 & 0.888 & -332 & - & - & - & - & - & - \\
\hline 0.849 & 0.851 & 511 & - & - & - & - & - & - \\
\hline 0.797 & 0.798 & 512 & - & - & - & - & - & - \\
\hline
\end{tabular}

*Indicates the respective $100 \%$ peak.

The TEM micrograph of nanocrystalline $\mathrm{Cu}_{0.95} \mathrm{Fe}_{0.05} \mathrm{O}$ $\left(900^{\circ} \mathrm{C} / 2 \mathrm{~h}\right)$ shown in Figure 5 has agglomerates of smaller particles due to annealing of the sample. The SAED pattern (inset of Figure 5) shows well-defined spots indicating formation of highly crystalline particles on annealing. The $d_{\mathrm{hkl}}$ and hkl values are tabulated in Table 4 . All the $d_{\mathrm{hkl}}$ values match with those of the parent $\mathrm{CuO}$ except for the $3.310 \AA$ $d_{\mathrm{hkl}}$, which has good coincidence with that of (012) plane of $\alpha-\mathrm{Fe}_{2} \mathrm{O}_{3}$. Hence the nanocrystalline $\mathrm{Cu}_{0.95} \mathrm{Fe}_{0.05} \mathrm{O}$ sample also has the possible secondary phases as observed in the SAED of bulk $\mathrm{Cu}_{0.95} \mathrm{Fe}_{0.05} \mathrm{O}$. The equation representing the sample formation with possible secondary phases is given as follows:

$$
\begin{aligned}
\mathrm{CuO} & +\mathrm{Fe}_{2} \mathrm{O}_{3} \frac{900^{\circ} \mathrm{C} / 12 \mathrm{~h}}{\Delta} \mathrm{Cu}_{(1-x)} \mathrm{Fe}_{x} \mathrm{O}+\mathrm{CuFe}_{2} \mathrm{O}_{4} \text { (cubic) } \\
& +\mathrm{Fe}_{2} \mathrm{O}_{3} \text { (Rhombohedral) }+\mathrm{CuO} .
\end{aligned}
$$


TABLE 4: $d_{\mathrm{hkl}}$ and hkl values of nanocrystalline $\mathrm{Cu}_{0.95} \mathrm{Fe}_{0.05} \mathrm{O}$ shown in comparison with possible secondary phases to indicate the closely situated $d_{\mathrm{hkl}}$ planes.

\begin{tabular}{|c|c|c|c|c|c|c|c|c|}
\hline \multirow{2}{*}{$\begin{array}{l}d_{\mathrm{hkl}}(\AA) \text { of } \\
\mathrm{Cu}_{0.95} \mathrm{Fe}_{0.05} \mathrm{O} \\
\text { from SAED }\end{array}$} & \multicolumn{2}{|c|}{$\begin{array}{l}\text { Monoclinic } \mathrm{CuO} \\
\text { JCPDS 65-2309 }\end{array}$} & \multicolumn{2}{|c|}{$\begin{array}{l}\text { Cubic } \mathrm{CuFe}_{2} \mathrm{O}_{4} \\
\text { JCPDS 77-0010 }\end{array}$} & \multicolumn{2}{|c|}{$\begin{array}{c}\text { Cubic } \mathrm{Fe}_{3} \mathrm{O}_{4} \\
\text { JCPDS 85-1436 }\end{array}$} & \multicolumn{2}{|c|}{$\begin{array}{c}\text { Rhombohedral } \\
\alpha-\mathrm{Fe}_{2} \mathrm{O}_{3} \text { JCPDS 80-2377 }\end{array}$} \\
\hline & $d_{\mathrm{hkl}}(\AA)$ & $\mathrm{hkl}$ & $d_{\mathrm{hkl}}(\AA)$ & $\mathrm{hkl}$ & $d_{\mathrm{hkl}}(\AA)$ & hkl & $d_{\mathrm{hkl}}(\AA)$ & hkl \\
\hline 3.310 & - & - & - & - & - & - & 3.682 & 012 \\
\hline 2.685 & 2.515 & $-111^{*}$ & 2.523 & $311^{*}$ & 2.530 & $311^{*}$ & 2.699 & $104^{*}$ \\
\hline 2.341 & 2.315 & 111 & 2.416 & 222 & 2.422 & 222 & 2.517 & 110 \\
\hline 2.086 & 1.955 & -112 & 2.092 & 400 & 2.098 & 400 & 2.078 & 202 \\
\hline 1.891 & 1.859 & -202 & 1.920 & 331 & 1.713 & 422 & 1.841 & 024 \\
\hline 1.684 & 1.708 & 020 & 1.708 & 422 & 1.615 & 511 & 1.694 & 116 \\
\hline 1.616 & 1.617 & 021 & 1.610 & 511 & 1.483 & 440 & 1.602 & 122 \\
\hline 1.514 & 1.501 & -113 & 1.479 & 440 & 1.418 & 531 & 1.486 & 214 \\
\hline 1.368 & 1.375 & 113 & 1.414 & 531 & 1.327 & 620 & 1.349 & 208 \\
\hline 1.217 & 1.257 & -222 & 1.208 & 444 & 1.279 & 533 & 1.213 & 223 \\
\hline 1.053 & 1.070 & 131 & 1.089 & 731 & 1.092 & 731 & 1.103 & 226 \\
\hline 0.917 & 0.951 & -331 & - & - & - & - & - & - \\
\hline 0.748 & - & - & - & - & - & - & - & - \\
\hline 0.636 & - & - & - & - & - & - & - & - \\
\hline
\end{tabular}

*Indicates the respective $100 \%$ peak.

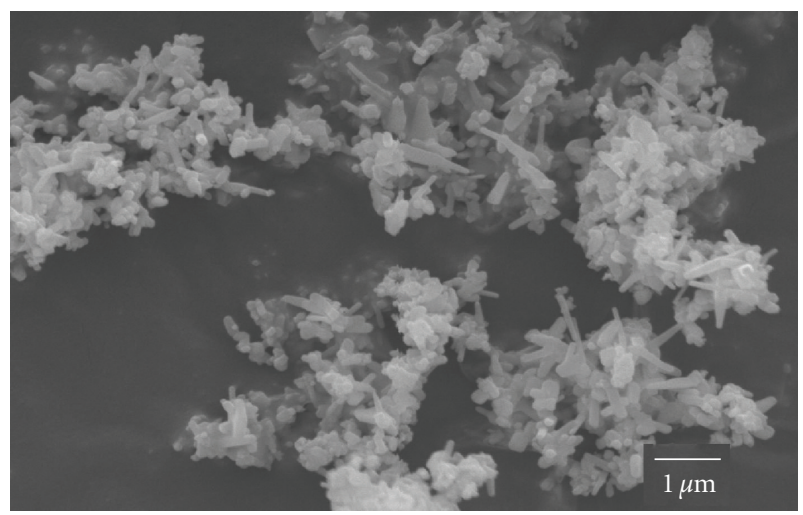

FiguRE 3: SEM micrograph of 40-hour refluxed nanocrystalline $\mathrm{Cu}_{0.95} \mathrm{Fe}_{0.05} \mathrm{O}$ showing the mixture of rod-like and platelet-like particles.

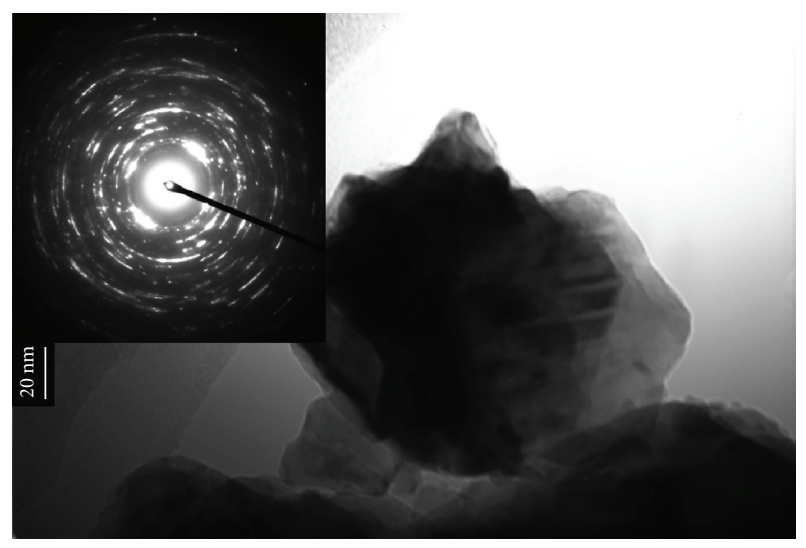

FIGURE 4: TEM micrograph and SAED pattern of bulk $\mathrm{Cu}_{0.95} \mathrm{Fe}_{0.05} \mathrm{O}$ $\left(900^{\circ} \mathrm{C} / 12 \mathrm{~h}\right)$.

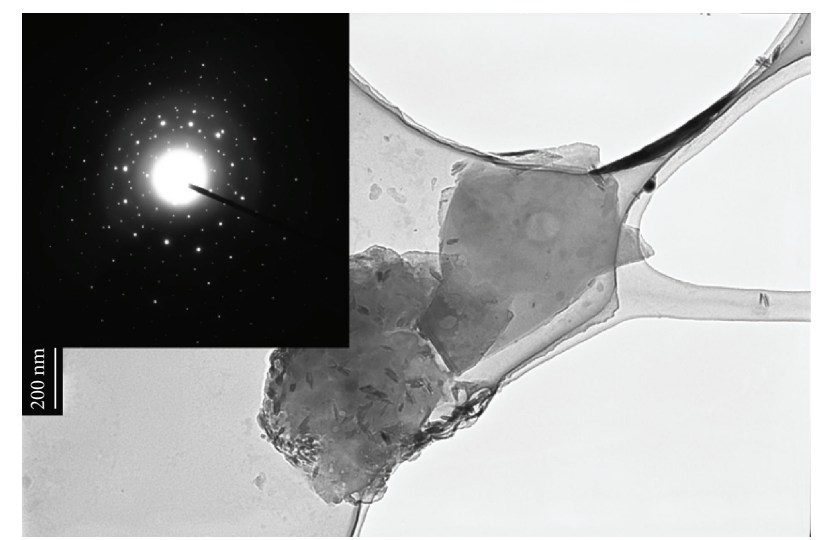

Figure 5: TEM micrograph and SAED pattern of nanocrystalline $\mathrm{Cu}_{0.95} \mathrm{Fe}_{0.05} \mathrm{O}\left(900^{\circ} \mathrm{C} / 2 \mathrm{~h}\right)$.

2.5. High-Pressure X-Ray Diffraction Using Synchrotron Radiation. Pressure is a fundamental thermodynamic degree of freedom available for basic investigations as well as for processing of materials. The effects of pressure are a result of changes in the band structure and of the energy content of a material produced by the reduction of inter atomic spacing. The study of the behavior of materials at high-pressures has been useful in the observation of new features of the physical and chemical properties. In order to produce appreciable effects on the properties of condensed phases, high-pressures of the order of hundreds or thousands of bars are required. Synchrotron radiation is a photon light source generated by high-energy electrons that are centripetally accelerated to relativistic velocities in the magnetic fields of a storage ring and are emitted in a narrow cone tangent to the orbit. Synchrotron radiation, 


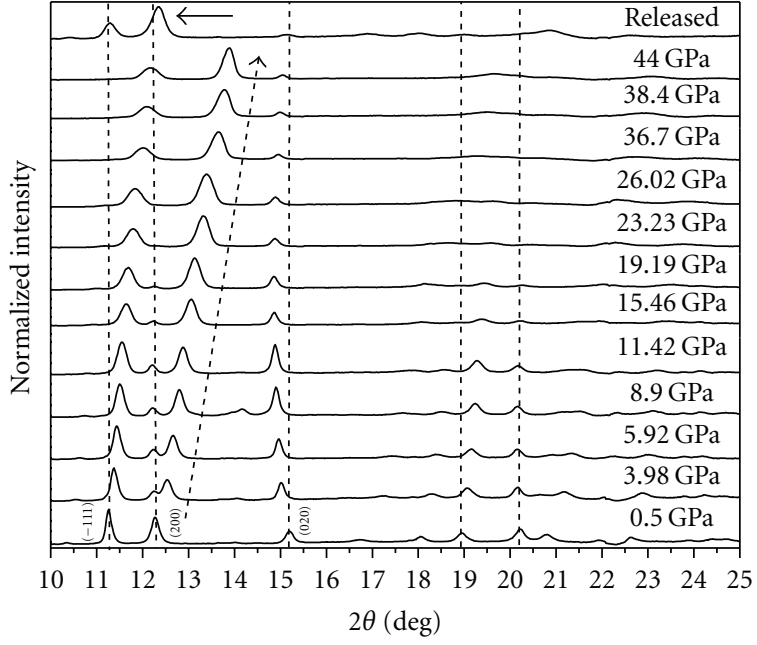

FIgUre 6: The XRD pattern of the $2 \%$ Fe-doped bulk $\mathrm{CuO}$ sample at different pressures using synchrotron radiation of wavelength $0.4564 \AA$.

because of unique properties like high brightness, wide energy spectrum, high degree of polarization, and high collimation has allowed extensive investigation of a variety of materials. The remarkable qualities of diamond such as high yield strength and transparency to radiation over a wide range of wavelengths have made it an obvious choice for the anvil materials making it possible to conduct highpressure X-ray diffraction measurements on materials at few hundreds of giga Pascal (GPa) using synchrotron radiation. Presence of secondary phases can be evidenced from the high-pressure X-ray diffraction measurements due to the fact that the elastic properties of $\mathrm{CuO}, \mathrm{Fe}$, and $\mathrm{CuFe}_{2} \mathrm{O}_{4}$ are different. Hence, we are motivated to study the sample at high-pressures to identify the presence of any hidden secondary phases.

High-Pressure XRD measurements were conducted in angle dispersive geometry using Mao-Bell type Diamond Anvil Cell. Experiment was performed using the synchrotron source at beamline 16IDB, High-Pressure Collaboration Access Team (HPCAT), Advanced photon source, Chicago, with a wavelength of $0.4564 \AA$. Bulk $\mathrm{CuO}: \mathrm{Fe}(2 \%)$ powder was loaded along with a few grains of platinum which acts as a pressure standard [33]. A stainless steel gasket of $50 \mu \mathrm{m}$ thickness indented using diamond anvils of culet size $300 \mu \mathrm{m}$, wherein a $100 \mu \mathrm{m}$ hole drilled serves as the sample chamber. The size of the incident beam was $10 \times 10 \mu \mathrm{m}^{2}$ and the diffracted beam was recorded on a Mar 3450 image plate. The diffraction measurements were carried out from $0.5 \mathrm{GPa}$ to $44 \mathrm{GPa}$ at room temperature and are shown in Figure 6. Each pattern was fitted and refined to monoclinic structure of $\mathrm{CuO}$ with space group $\mathrm{C}_{2} / \mathrm{c}$ using the software GSAS [34] with EXPGUI [35]. Though no structural transitions had been reported up to $100 \mathrm{GPa}$ in monoclinic $\mathrm{CuO}$ [36-40], the study helps in identifying the hidden phases based on the variation in compressibility.

In the case of $2 \% \mathrm{Fe}$-doped $\mathrm{CuO}$, application of pressure causes a shift in the diffraction peaks towards

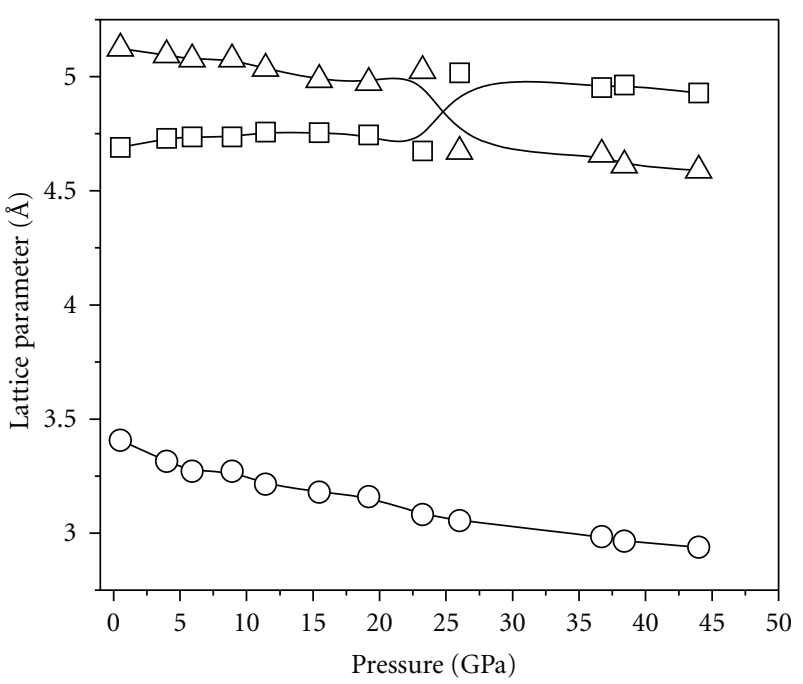

Refined lattice parameters
$-\square-a$
$-O-b$
$-\Delta-c$

FIGURE 7: Variation of lattice parameters with pressure of $2 \% \mathrm{Fe}-$ doped bulk $\mathrm{CuO}$ sample. The error in the lattice parameters is equivalent to the size of the markers.

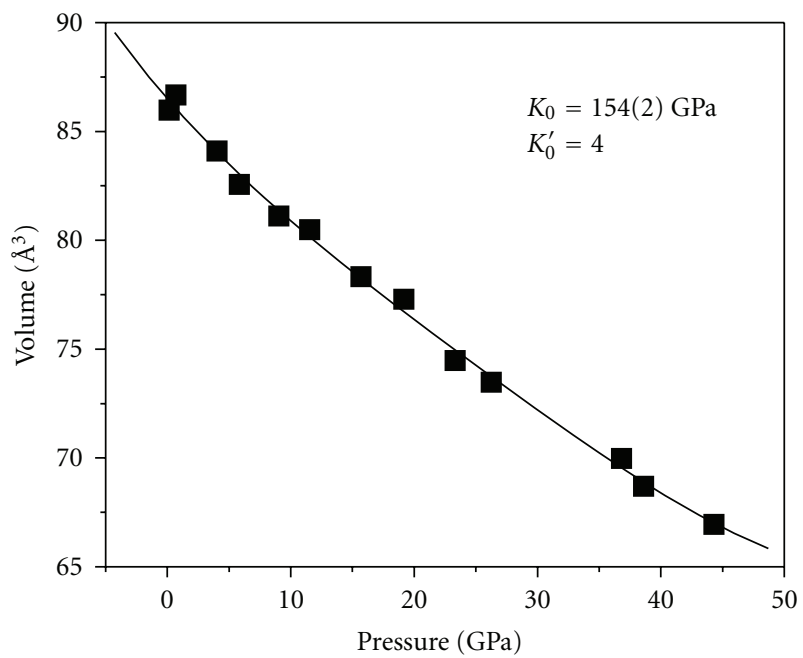

$2 \% \mathrm{Fe}$ doped $\mathrm{CuO}$

FIGURE 8: The 3rd-order BM-eos fit without any constraint on $\mathrm{K}_{0}^{\prime}$ for the $2 \% \mathrm{Fe}$-doped bulk $\mathrm{CuO}$ sample. The error in the sample volume is equivalent to the size of the markers.

higher angle indicating reduction in cell volume. Relative variation of refined lattice parameters as a function of pressure is shown in Figure 7. The overall trend on application of pressure on the " $b$ " and " $c$ " lattice parameters is to decrease them with increasing pressure and that " $a$ " increases gradually (Figure 7). The cell volume obtained from the refinement is found to decrease with pressure (Figure 8) and no abrupt change is 
observed indicating absence of structural transition. Literature reports indicate absence of structural transition from high-pressure electrical resistivity measurements in monoclinic $\mathrm{CuO}$ up to $100 \mathrm{GPa}[36,40]$.

Upon increasing the pressure, at $3.98 \mathrm{GPa}$, a peak clearly separates out from the (200) plane. Hence, when $\mathrm{CuO}$ gets compressed and shifts towards higher angle, an unknown peak becomes evident. With further increasing pressure, we observed that the $(-111)$ peak of monoclinic $\mathrm{CuO}$ shifts towards higher angle and tends to overlap with the unknown peak. As the pressure is further increased, the intensity of the unknown peak gradually decreases and completely vanishes at $26.02 \mathrm{GPa}$ before overlapping with the $(-111)$ plane of $\mathrm{CuO}$. Similar behavior has been observed in pure $\mathrm{CuO}$ itself (the results will be published elsewhere). Reimann and Syassen [41] observed changes in the Raman modes of pure $\mathrm{CuO}$ in high-pressure Raman measurements up to $34 \mathrm{GPa}$ which they explain as the changes in the internal structure parameter. Reimann and Syassen also report Malinowski to observe a structural anomaly in his X-ray diffraction measurement around $10 \mathrm{Gpa}$ (referred as private communication in back reference of [41]). Highpressure neutron diffraction studies by Ehrenberg et al. [38] suggest Jahn Teller type structural distortion seen below $8 \mathrm{GPa}$ in pure $\mathrm{CuO}$. Hence, appearance and suppression of an additional peak in the high-pressure XRD of $2 \%$ $\mathrm{Fe}$-doped $\mathrm{CuO}$ sample is also characteristic of pure $\mathrm{CuO}$. The phase transformation is similar to Jahn Teller-like distortion which occurs at high-pressure related to the variation of the bond angle with pressure. In addition to this observation, the absence of any other additional peaks evidences absence of secondary phases of them to be present below the limit of detection. The conclusion was drawn based on the variation of the bulk modulus of $\mathrm{CuO}$ and various secondary phases.

The $(-111)$ peak which was the maximum intensity peak at $0.5 \mathrm{GPa}$ loses its intensity gradually with increasing pressure, and at the same time, the (200) peak gain intensity. This may be due to the pressure-induced preferred orientation. This small internal structural distortion $[37,38,41]$ is found to be reversible upon releasing the pressure. However, there is a slight shift towards higher angle in the peak positions along with broadening, also, after releasing the pressure, the (200) plane becomes the peak with maximum intensity instead of $(-111)$ plane which may be due to the pressure-induced lattice strain and preferred orientation. However, pressureinduced substitution of a fraction of "Fe" at the "Cu" site might have also resulted which can be understood in more detail from high-pressure neutron diffraction measurement which is more sensitive to the magnetic moment of the elements in the sample when performed in the similar pressure range. The PV-equation of state fitted using the third-order Birch-Murnaghan equation of state (BM-eos) is given by

$$
\begin{aligned}
P= & \frac{3 K_{0}}{2} *\left[\left(\frac{V_{0}}{V}\right)^{7 / 3}-\left(\frac{V_{0}}{V}\right)^{5 / 3}\right] \\
& *\left[1+\frac{3}{4} *\left(K_{0}^{\prime}-4\right) *\left(\left(\frac{V_{0}}{V}\right)^{2 / 3}-1\right)\right],
\end{aligned}
$$

where $K_{0}$ is bulk modulus, $K_{0}^{\prime}$ is derivative of bulk modulus with pressure, $V_{0}$ is zero pressure volume, and $V$ is volume at pressure $P$. The value of $K_{0}^{\prime}$ set to 4 shown in Figure 8 indicates a steady decrease in volume on increasing the pressure with no abrupt change indicating absence of phase transition. Hence, absence of secondary phases is evident from the high pressure XRD data and even if present, it is well below the level of detection.

2.6. TGA Results. To identify the effect of "Fe\%" doping on the $T_{N}$ of the samples, the TGA measurements were performed with a small applied field $(\approx 20$ Oe) to determine the $T_{N}$ as a function of temperature. The measurement was performed in $\mathrm{N}_{2}$ atmosphere with a heating rate of $10^{\circ} \mathrm{C} / \mathrm{min}$ up to $600^{\circ} \mathrm{C}$. For the 50 hour refluxed nanocrystalline $\mathrm{Cu}_{0.95} \mathrm{Fe}_{0.05} \mathrm{O}$ sample, the $T_{N}$ was found to increase with decreasing crystallite size (Figure 9). The increase in magnetization prior to $T_{N}$ in the TGA curves observed for $\mathrm{Cu}_{0.95} \mathrm{Fe}_{0.05} \mathrm{O}$ is due to Hopkinson effect which is also reported in the case of $\mathrm{NiFe}_{2} \mathrm{O}_{4}$ [42]. The bulk $\mathrm{Cu}_{0.95} \mathrm{Fe}_{0.05} \mathrm{O}$ had a $T_{N}$ of $458^{\circ} \mathrm{C}$, whereas a $T_{N}$ of $479^{\circ} \mathrm{C}\left(900^{\circ} \mathrm{C} / 12 \mathrm{~h}\right)$ for the $49 \mathrm{~nm}$ sample and that of $486^{\circ} \mathrm{C}\left(900^{\circ} \mathrm{C} / 2 \mathrm{~h}\right)$ for the $25 \mathrm{~nm}$ sample were observed. Thus the decrease in crystallite size increases the $T_{N}$. However, this variation of $T_{N}$ may be due to the size effect of the copper ferrite phase that has formed within the sample. To avoid the effect of particle size on $T_{N}$, we studied the bulk samples prepared by ceramic method to trace the original trend of variation of $T_{N}$ with "Fe" concentration in $\mathrm{CuO}$. The $T_{N}$ observed for "Fe"doped $\mathrm{CuO}$ bulk samples is shown in Table 5. There was no noticeable trend in the variation of $T_{N}$. The $T_{N}$ remained around $460^{\circ} \mathrm{C}$ irrespective of the " $\mathrm{Fe} \%$ ", indicating that one major secondary phase had formed within the sample. This $T_{N}$ value has good coincidence with the $T_{N}$ of cubic $\mathrm{CuFe}_{2} \mathrm{O}_{4}$, which is $465^{\circ} \mathrm{C}$ [43], whereas the $T_{N}$ of cubic $\mathrm{Fe}_{3} \mathrm{O}_{4}$ is $585^{\circ} \mathrm{C}$. This observation is a clear experimental evidence that the observed hysteresis behaviour is from the phase-segregated $\mathrm{CuFe}_{2} \mathrm{O}_{4}$. This confirms that the "Fe" does not get substituted into the substitutional site of $\mathrm{CuO}$ even for $1 \%$ of " $\mathrm{Fe}$ " in $\mathrm{CuO}$ to effect any change in the property of $\mathrm{CuO}$; rather it favors the formation of cubic $\mathrm{CuFe}_{2} \mathrm{O}_{4}$ as segregates within the sample whereas Park et al. [24] do not report any ferrite impurity phase; they instead discuss intrinsic ferromagnetic behaviour in $2 \%{ }^{~ " 57} \mathrm{Fe}$ "-doped $\mathrm{CuO}$ mediated by carriers localized around the oxygen vacancies studied by Mössbauer measurements.

For "Fe"-doped bulk $\mathrm{CuO}$, the $T_{N}$ is found to be around $460^{\circ} \mathrm{C}$. The $T_{N}$ of $\mathrm{Fe}_{3} \mathrm{O}_{4}$ is $585^{\circ} \mathrm{C}$ and is higher than the $T_{N}$ observed for bulk $\mathrm{Cu}_{0.95} \mathrm{Fe}_{0.05} \mathrm{O}$ whereas the $T_{N}$ of cubic $\mathrm{CuFe}_{2} \mathrm{O}_{4}$ is $465^{\circ} \mathrm{C}$ [43]. The $T_{N}$ of bulk $\mathrm{CuO}$ doped with $\mathrm{Fe}$ to various extents was very close to that of cubic $\mathrm{CuFe}_{2} \mathrm{O}_{4}$. Hence no appreciable variation in $T_{N}$ was found with varying "Fe" concentration. Hence, even the $1 \%$ and $2 \%$ "Fe"-doped $\mathrm{CuO}$ is inevitably found to possess copper ferrite phase. $\mathrm{CuFe}_{2} \mathrm{O}_{4}$ when quenched or rapidly cooled (from above $760^{\circ} \mathrm{C}$ ), takes cubic structure with $a=8.37 \AA$. If cooled slowly, it attains tetragonal phase with $a=8.22 \AA$ and $c=$ $8.70 \AA$ [43]. Since all the samples were furnace cooled from 
TABLE 5: Neel transition temperature of bulk $\mathrm{CuO}$ with "Fe" doped to various extent and pure $\mathrm{CuFe}_{2} \mathrm{O}_{4}$.

\begin{tabular}{ll}
\hline \% of " $\mathrm{Fe}^{\text {" in } \mathrm{CuO}}$ & $\begin{array}{l}\text { Neel transition } \\
\text { temperature }\left(T_{N}\right){ }^{\circ} \mathrm{C}\end{array}$ \\
\hline $\mathrm{Cu}_{0.99} \mathrm{Fe}_{0.01} \mathrm{O}$ & 463 \\
$\mathrm{Cu}_{0.98} \mathrm{Fe}_{0.02} \mathrm{O}$ & 464 \\
$\mathrm{Cu}_{0.97} \mathrm{Fe}_{0.03} \mathrm{O}$ & 456 \\
$\mathrm{Cu}_{0.96} \mathrm{Fe}_{0.04} \mathrm{O}$ & 480 \\
$\mathrm{Cu}_{0.95} \mathrm{Fe}_{0.05} \mathrm{O}$ & 458 \\
$\mathrm{Cu}_{0.90} \mathrm{Fe}_{0.10} \mathrm{O}$ & 481 \\
$\mathrm{CuFe}_{2} \mathrm{O}_{4}$ & 483 \\
\hline
\end{tabular}

above $900^{\circ} \mathrm{C}$, the cubic phase of $\mathrm{CuFe}_{2} \mathrm{O}_{4}$ is predominantly observed. Hence the observed magnetic property for these samples is not fully intrinsic in nature; instead they have a major contribution from the cubic $\mathrm{CuFe}_{2} \mathrm{O}_{4}$ phase leading to a "pinned type" composite magnetic material. Similar observation of contribution from $\mathrm{NiFe}_{2} \mathrm{O}_{4}$ phase has also been reported in the case of Fe-doped $\mathrm{NiO}$ by Douvalis et al. from Mössbauer measurements [44].

2.7. Magnetization Results. The magnetization measurements were performed in a Vibrating Sample Magnetometer (VSM) (EG and G Princeton Applied Research VSM 4500) at $300 \mathrm{~K}$. The $\mathrm{Cu}_{0.95} \mathrm{Fe}_{0.05} \mathrm{O}$ samples show clear hysteresis behaviour at room temperature (Figure 10) whereas Borzi et al. had observed paramagnetic behaviour from the Mössbauer measurements for "Fe"-doped $\mathrm{CuO}$, at room temperature [23]. Park et al. [24] have reported ferromagnetic hysteresis behavior for annealing above $500^{\circ} \mathrm{C}$; however they explain it as intrinsic behavior due to indirect coupling among the $\mathrm{Fe}^{3+}$ ions via a localized carrier at oxygen vacancy. Treatment at $500^{\circ} \mathrm{C}$ is not sufficient to completely crystallize out $\mathrm{CuFe}_{2} \mathrm{O}_{4}$. We could also observe a paramagnetic-like behaviour for the samples annealed at $500^{\circ} \mathrm{C} / 2 \mathrm{~h}$ from VSM (bottom inset of Figure 10) and the loops did not saturate but were found to show hysteresis at room temperature when annealed at $900^{\circ} \mathrm{C} / 2 \mathrm{~h}$. Hence, after annealing at $900^{\circ} \mathrm{C}$ in air, the magnetization curve becomes smooth and the corresponding SEM micrograph also presented only plateletlike particles (not shown here). The $M_{\max }$ values were found to increase with increasing refluxing hour (top inset of Figure 10) and also found to increase with increasing " $\mathrm{Fe} \%$ " in nanocrystalline $\mathrm{CuO}$ samples refluxed for 50 hour and annealed at $900^{\circ} \mathrm{C} / 2 \mathrm{~h}$ in air (Figure 11). Inset of Figure 11 shows the comparison of the magnetization data of all the samples with pure copper ferrite; note the large difference in magnetization. This may be presumably due to increasing volume fraction of $\mathrm{CuFe}_{2} \mathrm{O}_{4}$ within the samples. The nonsaturation of loops may be due to the following reasons: (a) presence of clusters of undoped paramagnetic $\mathrm{CuO}$ (at $300 \mathrm{~K}$ ), and (b) incomplete formation of ferrite secondary phases, which are responsible for the observed dominant magnetic behaviour.

In our case of "Fe"-doped $\mathrm{CuO}$, ferrimagnetic correlations among " $\mathrm{Fe}^{2+}$ " atoms substituting the "Cu" site may lead

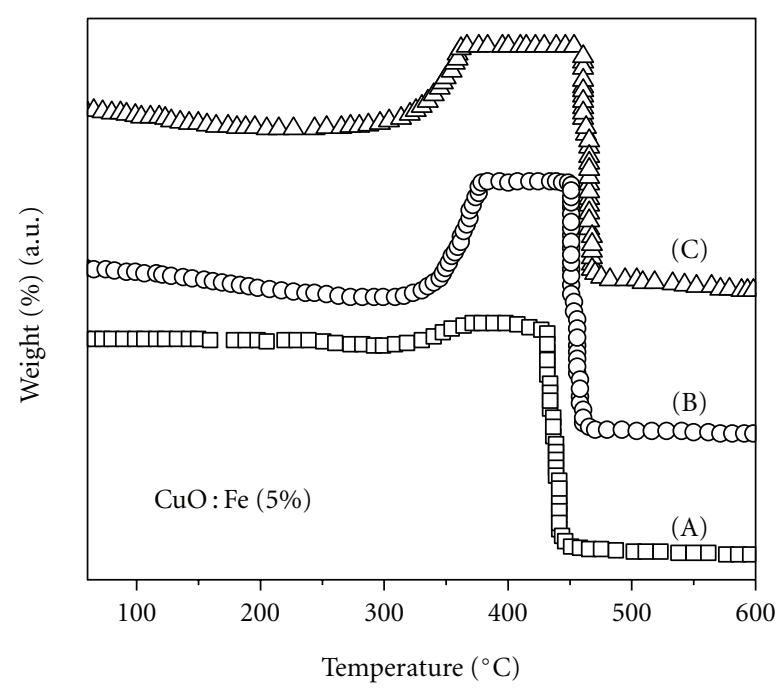

FIgUre 9: TGA results of samples: (A) bulk $\mathrm{Cu}_{0.95} \mathrm{Fe}_{0.05} \mathrm{O}, \mathrm{T}_{N}=$ $458^{\circ} \mathrm{C}$, (B) nanocrystalline $\mathrm{Cu}_{0.95} \mathrm{Fe}_{0.05} \mathrm{O}$ annealed at $900^{\circ} \mathrm{C} / 12 \mathrm{~h}$, $T_{N}=479^{\circ} \mathrm{C},(\mathrm{C})$ nanocrystalline $\mathrm{Cu}_{0.95} \mathrm{Fe}_{0.05} \mathrm{O}$ annealed at $900^{\circ} \mathrm{C}$ $/ 2 \mathrm{~h}, T_{N}=486^{\circ} \mathrm{C}$.

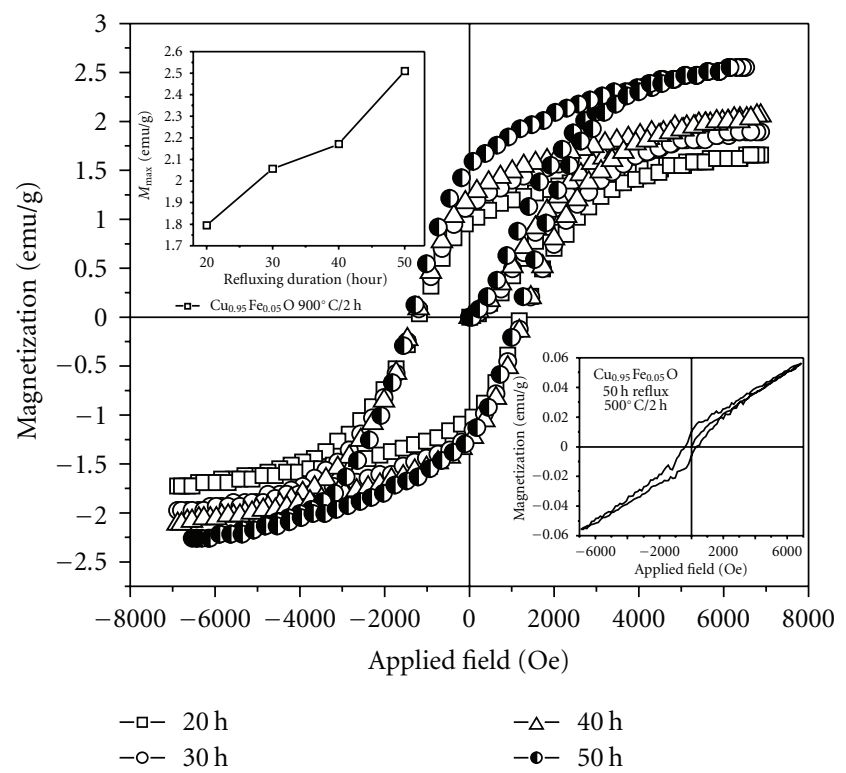

Figure 10: Hysteresis behavior of $\mathrm{Cu}_{0.95} \mathrm{Fe}_{0.05} \mathrm{O}$ refluxed for various durations and annealed at $900^{\circ} \mathrm{C} / 2 \mathrm{~h}$. Bottom inset represents the paramagnetic behavior of 50 hour refluxed $\mathrm{Cu}_{0.95} \mathrm{Fe}_{0.05} \mathrm{O}$ annealed at $500^{\circ} \mathrm{C} / 2 \mathrm{~h}$. Top inset represents the increase in $M_{\max }$ value with increasing refluxing period.

to an ordered spin configuration enhancing the magnetic susceptibility. But this effect is masked by the dominant ferromagnetic signal from the $\mathrm{CuFe}_{2} \mathrm{O}_{4}$ phase, at $300 \mathrm{~K}$. Though the observed magnetic behavior at $300 \mathrm{~K}$ is dominated by the $\mathrm{CuFe}_{2} \mathrm{O}_{4}$ phase, other plausible contribution comes from the "Fe ${ }^{2+}$ " substituted in "Cu" site of $\mathrm{CuO}$. The dominant ferromagnetic signal from $\mathrm{CuFe}_{2} \mathrm{O}_{4}$ masks magnetic contribution from " $\mathrm{Fe}^{2+}$ " substituted in $\mathrm{CuO}$ and pertains from reaching a conclusive hypothesis. One has to 


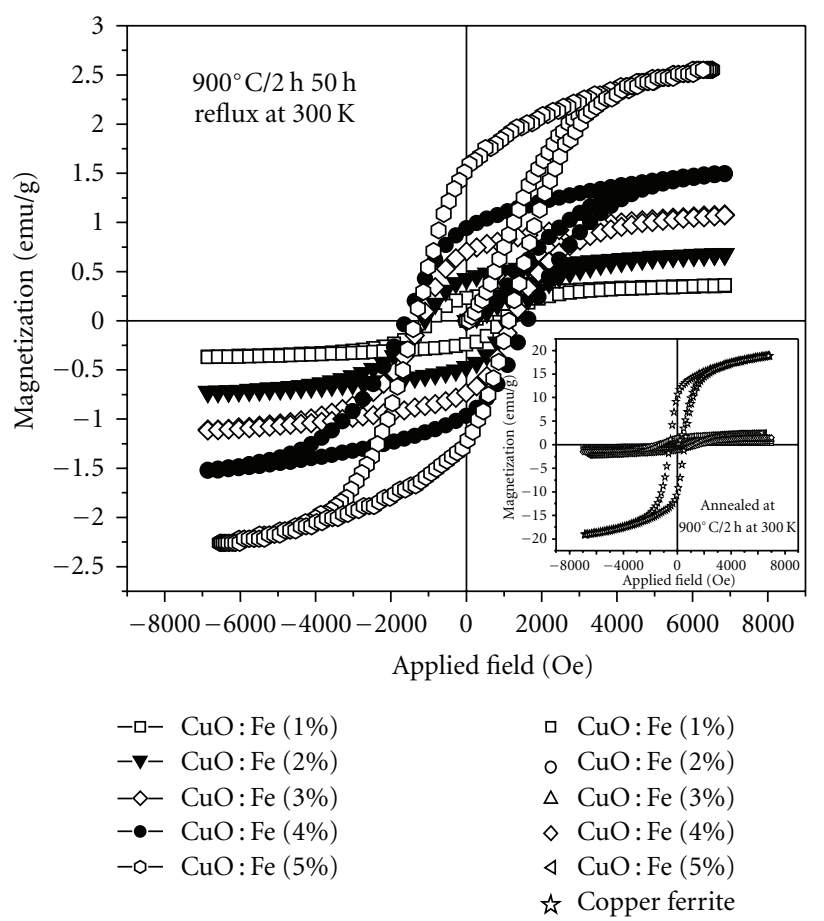

FIgURE 11: Increase in magnetization $\left(M_{\max }\right)$ as a function of $\%$ of " $\mathrm{Fe}$ " in $\mathrm{CuO}$ at $300 \mathrm{~K}$ for the 50 -hour refluxed nanocrystalline sample annealed at $900^{\circ} \mathrm{C} / 2 \mathrm{~h}$ in air. Inset shows the comparison with pure copper ferrite.

do more work to explain from the standpoint of " $\mathrm{Fe}^{2+}$ " substituting the "Cu" site by delineating the contribution from the segregated $\mathrm{CuFe}_{2} \mathrm{O}_{4}$ phase.

The magnetization measurements on bulk $1 \%$ and $2 \% \mathrm{Fe}$ - doped $\mathrm{CuO}$ performed at $77 \mathrm{~K}$ showed distorted hysteresis loops (Figure 12). This is because the measurement temperature is well below the Neel temperature $\left(T_{N}\right)$ of $\mathrm{CuO}$. The noncollinear spin arrangement due to partial Fe substitution at the $\mathrm{Cu}$ site now weakens and the spin alignment tend towards (perfect anticollinear) antiferromagnetic arrangement. The distorted hysteresis (Figure 12) showed a loop shift away from the $M=0$ (inset of Figure 12) which is known as exchange bias [45]. Exchange bias is commonly observed in a mixture of antiferromagnetic (AFM) and ferromagnetic (FM) type compounds [46]. Susceptibility studies also show three dimensional AFM behavior below $212 \mathrm{~K}$ [47].

The $1 \%$ "Fe"-doped $\mathrm{CuO}$ showing ferrimagnetic behavior at $300 \mathrm{~K}$ is found to present distorted signal at $77 \mathrm{~K}$. At $77 \mathrm{~K}, \mathrm{CuO}$ is antiferromagnetic; hence the spins tend towards anticollinear arrangement leading to decrease in magnetization. However, if reasonable quantity of $\mathrm{CuFe}_{2} \mathrm{O}_{4}$ is present, then, an increase in magnetization at $77 \mathrm{~K}$ should have been observed, but, to the contrary it deteriorates. At $77 \mathrm{~K}$, the sample becomes an antiferromagneticferrimagnetic composite mixture, whereas at $300 \mathrm{~K}$, it is a paramagnetic-ferrimagnetic mixture. At $77 \mathrm{~K}$, the loss of hysteresis behavior could be explained based on the antiferromagnetic transition occurring in $\mathrm{CuO}$ in which spins

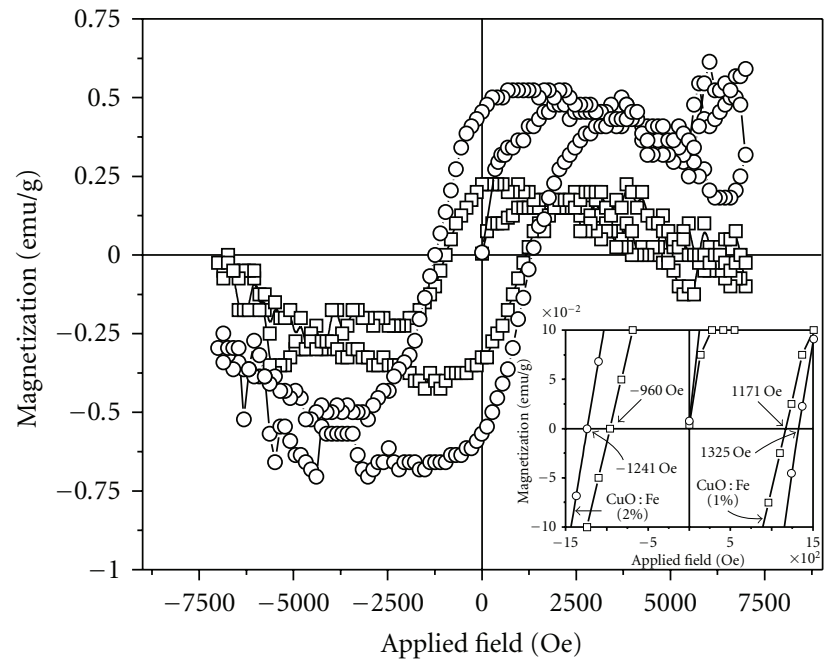

$$
\begin{aligned}
& \text { At } 77 \mathrm{~K} \\
& -\square-\mathrm{CuO}: \mathrm{Fe}(1 \%) \\
& - \text { o- } \mathrm{CuO}: \mathrm{Fe}(2 \%)
\end{aligned}
$$

FIGURE 12: Hysteresis behavior of bulk 1 and 2\% "Fe"-doped $\mathrm{CuO}$ samples annealed at $900^{\circ} \mathrm{C} / 12 \mathrm{~h}$ in air measured at $77 \mathrm{~K}$. Inset shows the exchange bias behavior.

in the anticollinear arrangement dominate by distorting the ferrimagnetic arrangement of $\mathrm{CuFe}_{2} \mathrm{O}_{4}$.

\section{Results and Discussion}

Based on the above given experimental observations, formation of cubic $\mathrm{CuFe}_{2} \mathrm{O}_{4}$ is confirmed. However one could not discard the candidature of $\mathrm{CuO}$ to be an efficient material from applications point of view. This is because, even if $\mathrm{CuFe}_{2} \mathrm{O}_{4}$ phase persists in $\mathrm{CuO}$, the material can be utilized for the fabrication of magnetic tunnel junction (MTJ-) like structures and also there may be an intrinsic magnetic behaviour due to "Fe" substitution in the "Cu" site. The magnetization measurements on $\mathrm{CuO}$, with $\mathrm{CuFe}_{2} \mathrm{O}_{4}$ as an impurity, show large variation in $M_{\max }$ and $H_{C}$ as observed from the magnetization experiments which are essential criteria for an MTJ. There are a reasonable number of literature reports on MTJs composed of partly or all oxide layers. MTJs using $\mathrm{Al}_{2} \mathrm{O}_{3}$ barrier and an Feoxide layer converted to ferromagnetic $\mathrm{Fe}_{3} \mathrm{O}_{4}$ by annealing have been demonstrated [48]. Heterostructures MTJ device using $\mathrm{Ti}_{(1-x)} \mathrm{Co}_{x} \mathrm{O}_{(2-\delta)}$ DMS as the spin injection electrode has also been demonstrated [49]. All oxide MTJ's such as $\mathrm{Fe}_{3} \mathrm{O}_{4} / \mathrm{MgO} / \mathrm{Fe}_{3} \mathrm{O}_{4}, \mathrm{Fe}_{3} \mathrm{O}_{4} / \mathrm{CoCr}_{2} \mathrm{O}_{4} / \mathrm{La}_{0.7} \mathrm{Sr}_{0.3} \mathrm{MnO}_{3}$ (LSMO) have also been reported [50-53]. In the case of all oxide $\mathrm{Fe}_{3} \mathrm{O}_{4} / \mathrm{Mg}_{2} \mathrm{TiO}_{4}$ (MTO)/LSMO structure, Alldredge et al. [54] reported minimal mismatch due to similar spinel structure at the $\mathrm{Fe}_{3} \mathrm{O}_{4} / \mathrm{MTO}$ interface. They have also reported coercive fields of about 200 and 600 Oe for the LSMO and $\mathrm{Fe}_{3} \mathrm{O}_{4}$ layers, respectively. Diode effect has been observed in all oxide $\mathrm{Sr}_{2} \mathrm{FeMoO}_{6} / \mathrm{SrTiO}_{3} / \mathrm{CoFe}_{2} \mathrm{O}_{4} \mathrm{MTJ}$ by Fix et al. [55]. The coercive field of the two magnetic electrodes in an MTJ should be well separated and the 
magnetization reversal of these layers should be abrupt. Hence without attaining single phase one may try to use this material for multilayer switching applications considering it as a composite material of "pinned" type magnetization; the discussion in this point of view is given in this section.

3.1. Pinned Type Composite Magnetic Material. The VSM measurements on $\mathrm{CuO}$ doped with varying " $\mathrm{Fe} \%$ " show the $M_{\max }$ value to increase. Since $\mathrm{CuFe}_{2} \mathrm{O}_{4}$ present in the sample is mainly responsible for the observed magnetic behavior, then with increasing " $\mathrm{Fe} \%$ " in $\mathrm{CuO}$, the volume fraction of $\mathrm{CuFe}_{2} \mathrm{O}_{4}$ has to increase; that is, the samples should tend towards more soft nature, with high $M_{\max }$ and low $H_{C}$. Instead, we observe a linear increase in $M_{\max }$ and an increase in $H_{C}$ with increasing " $\mathrm{Fe} \%$ " instead of decrease in $H_{C}$ (Figure 13) for 1, 4, and 7\% "Fe"-doped $\mathrm{CuO}$, which may be due to domain wall pinning effects. The spontaneous magnetic moment per " $\mathrm{Fe}$ " atom in $\mathrm{CuO}$ for 1 , 4, and 7\% are $0.0057 \mu_{B}, 0.0168 \mu_{B}$, and $0.0276 \mu_{B}$, respectively. Besides the enhancement of $H_{C}$, the squareness ratio, $M_{R} / M_{S}$ also increases with " $\mathrm{Fe} \%$ " in $\mathrm{CuO}$. The value of squareness ratio of 1,4 and $7 \%$ "Fe" doped $\mathrm{CuO}$ is $0.249,0.448$, and 0.519 , respectively. This is an indication that the "Fe"-doped $\mathrm{CuO}$ tend towards "hard" nature in spite of the presence of soft magnetic $\mathrm{CuFe}_{2} \mathrm{O}_{4}$.

The $H_{C}$ value of $7 \%$ "Fe"-doped bulk $\mathrm{CuO}(620 \mathrm{Oe})$ is three times greater than the value of $1 \%$ "Fe"-doped bulk $\mathrm{CuO}$ (202 Oe) (Figure 13 inset) indicating that the layer of "Fe" composition-varied $\mathrm{CuO}$ thin films may show exchange coupling. High $\mathrm{H}_{\mathrm{C}} \mathrm{CuO}$ layer may be used as a "pinned" layer in MTJ structures. The $H_{C}$ of bulk and nanocrystalline $\mathrm{Cu}_{0.95} \mathrm{Fe}_{0.05} \mathrm{O}$ was found to be $236 \mathrm{Oe}$ and $1225 \mathrm{Oe}$, respectively. The $H_{C}$ increased five times in magnitude in the nanocrystalline sample (Figure 14). The $M_{\max }$ value of nanocrystalline $\mathrm{CuO}: \mathrm{Fe}$ ( $1 \%$ to $5 \%$ ) is found to increase with "Fe" concentration (Figure 14 inset). These aspects could induce exchange coupling which is desirable for device fabrication if one could stabilize a single phase $\mathrm{Cu}-\mathrm{Fe}-\mathrm{O}$ solid solution without any ferrite formation by adopting different preparation techniques or by preparing a sample with homogenously dispersed $\mathrm{CuFe}_{2} \mathrm{O}_{4}$ in $\mathrm{CuO}$.

By comparing the virgin magnetization curve in the hysteresis loop, one recognizes two qualitatively different kinds of behavior: (i) nucleation type and (ii) pinning type [56]. In a nucleation type magnet, the virgin curve is steep and saturation is reached under fields much lower than the saturation loop coercive field. Domain walls are present in the virgin state and the fact that the material can be easily saturated shows that walls are free to move and do not experience any important pinning effects. Once the virgin domain structure has been swept away, the formation of reversed domains becomes a difficult process, and the demagnetization curve is characterized by a substantial coercivity.

In a pinning type magnet, fields of the order of the saturation loop coercive field are required to saturate the material even when one starts from the virgin state. This indicates that domain wall pinning is the main mechanism responsible for coercivity. Domain wall motion is

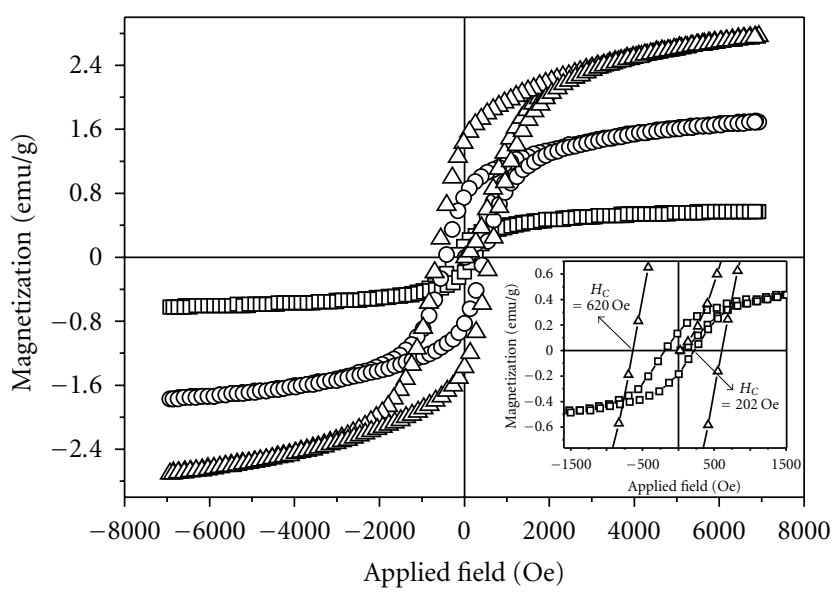

$$
\begin{array}{ll}
\text { Ceramic method } & \\
\square \mathrm{CuO}: \mathrm{Fe}(1 \%) & -\square-\mathrm{Fe}(1 \%) \\
\circ \mathrm{CuO}: \mathrm{Fe}(4 \%) & -\Delta-\mathrm{Fe}(7 \%) \\
\triangle \mathrm{CuO}: \mathrm{Fe}(7 \%) &
\end{array}
$$

Figure 13: Hysteresis loop of 1\%, 4\%, and 7\% "Fe"-doped bulk $\mathrm{CuO}$ at $300 \mathrm{~K}$. Inset shows the large variation in coercivity of $1 \%$ and $7 \%$ "Fe"-doped samples.

the dominant mechanism and the loop width is mainly determined by wall pinning effects [56]. The impediments to wall motion will determine the coercive field. The physical picture summarized by the term wall pinning is one where the impediments to wall motion arise from some form of structural disorder; dispersed phases with magnetic properties different from those of the matrix, as well as nonmagnetic inclusions or cavities, may also be important sources of pinning. The strength of the pinning effect may critically depend on the dimensionality of the pinning sources. The strength, density, and dimensionality of pinning centers can affect the value of $H_{C}$. Though the solubility of " $\mathrm{Fe}$ " in $\mathrm{CuO}$ is very much limited, a very small quantity of any immiscible component will always dissolve in another component, as this increases the configurational entropy and lowers the free energy of the crystal [57]. Hence, though the formation of $\mathrm{CuFe}_{2} \mathrm{O}_{4}$ is more favorable while trying to dope "Fe" in $\mathrm{CuO}$, a fraction of "Fe" also enters into the $\mathrm{Cu}^{2+}$ site as substitutional impurity. Hence contribution from intrinsic magnetization from the fraction of $\mathrm{Cu}-\mathrm{Fe}-\mathrm{O}$ substitutional solid solution formed within the sample apart from the composite like behavior of paramagnetic $\mathrm{CuO}$ dispersed with $\mathrm{CuFe}_{2} \mathrm{O}_{4}$ particles cannot be disregarded. Hence, one has to really ascertain its effect delineating the major magnetic contribution from the segregated $\mathrm{CuFe}_{2} \mathrm{O}_{4}$ phase. The intrinsic magnetic behavior could result from the spin alignment induced by the fraction of "Fe" substituting the "Cu" site. One could also argue that as the "Fe\%" in $\mathrm{CuO}$ increases, the fraction of "Fe" substituting the cationic site also increases reasonably. However to cross check this argument, neutron diffraction measurements at ambient and at high-pressures are necessary.

3.2. Comparison of $1 \% \mathrm{Fe}$ Doped $\mathrm{CuO}$ and $\mathrm{Cu}_{2} \mathrm{O}$. The results of $1 \%$ "Fe"-doped $\mathrm{Cu}_{2} \mathrm{O}$ imply us to elucidate the role of 


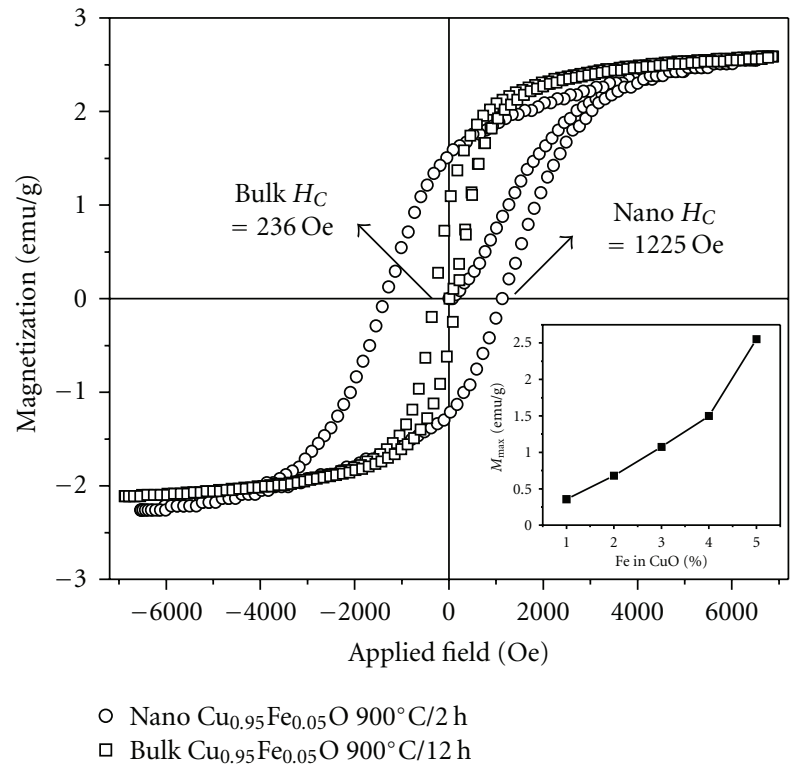

Figure 14: Room temperature hysteresis loops of bulk and nanocrystalline (50 hour refluxed, annealed at $900^{\circ} / 2 \mathrm{~h}$ ) $\mathrm{Cu}_{0.95} \mathrm{Fe}_{0.05} \mathrm{O}$ showing five-fold increase in coercivity. Inset shows the increase in $M_{\max }$ value with increasing " $\mathrm{Fe}$ " concentration in nanocrystalline samples.

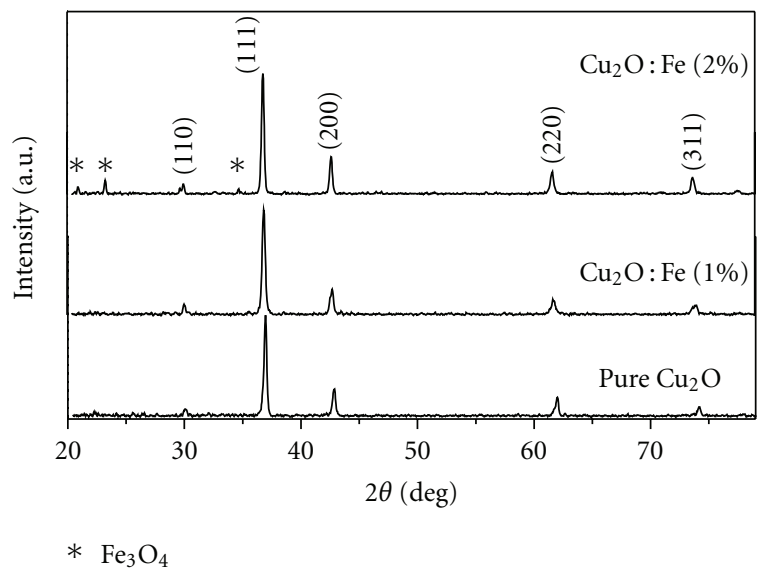

Figure 15: XRD patterns of pure $\mathrm{Cu}_{2} \mathrm{O}, 1 \%$ "Fe"-doped single phase $\mathrm{Cu}_{2} \mathrm{O}$, and $2 \%$ " $\mathrm{Fe}$ "-doped $\mathrm{Cu}_{2} \mathrm{O}$ with impurity peaks of $\mathrm{Fe}_{3} \mathrm{O}_{4}$.

substitutional "Fe" in $\mathrm{CuO}$. The non-observation of room temperature ferromagnetic behaviour in diamagnetic $\mathrm{Cu}_{2} \mathrm{O}$ doped with $1 \%$ of " $\mathrm{Fe}$ " is another indirect support for the plausible intrinsic magnetization of "Fe"-doped $\mathrm{CuO}$. The XRD pattern of pure $\mathrm{Cu}_{2} \mathrm{O}(a=4.253 \AA)$ confirmed the cubic structure of $\mathrm{Cu}_{2} \mathrm{O}$ and is shown in comparison with $1 \%$ and $2 \%$ " $F$ "-doped $\mathrm{Cu}_{2} \mathrm{O}$ in Figure 15. Single phase $1 \%$ "Fe"-doped $\mathrm{Cu}_{2} \mathrm{O}$ was achieved by optimizing the concentration of $\mathrm{N}_{2} \mathrm{H}_{4}$ and the stirring duration. The XRD pattern of $2 \%$ " $F e$ "-doped $\mathrm{Cu}_{2} \mathrm{O}$ showed secondary phases of $\mathrm{Fe}_{3} \mathrm{O}_{4}$ which is shown in comparison with pure $\mathrm{Cu}_{2} \mathrm{O}$ in Figure 15. The compositional analysis by EDAX confirmed the near stoichiometry of $1 \%$ and $2 \%$ "Fe"-doped $\mathrm{Cu}_{2} \mathrm{O}$ as it is a random alloy. Reproducibility was confirmed by numerous

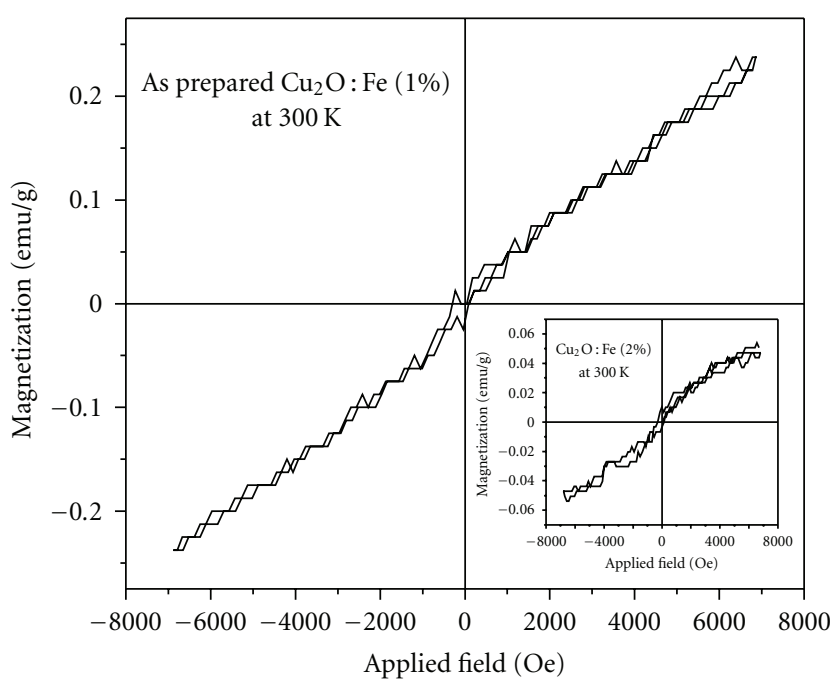

Figure 16: Paramagnetic behavior of $1 \%$ Fe-doped $\mathrm{Cu}_{2} \mathrm{O}$ at $300 \mathrm{~K}$. Inset shows the same for $2 \%$ "Fe"-doped $\mathrm{Cu}_{2} \mathrm{O}$.

trials because formation of $\mathrm{Cu}_{2} \mathrm{O}$ by wet chemistry method fairly has a chance of formation of $\mathrm{CuFe}_{2} \mathrm{O}_{4}$ and metallic "Fe" on over reduction with $\mathrm{N}_{2} \mathrm{H}_{4}$. Moreover the as-prepared samples were crystalline in nature due to preparation by reducing with $\mathrm{N}_{2} \mathrm{H}_{4}$. Hence annealing was not performed for any of the samples. Moreover, copper (I) oxide, being a meta stable phase, turns into a stable copper (II) oxide when heated above $160^{\circ} \mathrm{C}$ in air. The magnetization measurements on $1 \%$ " $F$ "-doped $\mathrm{Cu}_{2} \mathrm{O}$ at $300 \mathrm{~K}$ showed paramagnetic behavior (Figure 16) [30]. Pure $\mathrm{Cu}_{2} \mathrm{O}$ is diamagnetic, but on doping with "Fe", the material exhibits paramagnetic behavior. The low temperature measurements at $77 \mathrm{~K}$ show clear diamagnetic behavior (not shown here) indicating the non-ferromagnetic role played by impurities present, if any. The magnetization measurements on $2 \%$ "Fe"-doped $\mathrm{Cu}_{2} \mathrm{O}$ sample, though having $\mathrm{Fe}_{3} \mathrm{O}_{4}$ phase, did not show clear room temperature ferromagnetism (Inset of Figure 16), whereas $1 \%$ and $2 \%$ "Fe"-doped $\mathrm{CuO}$ presents clear ferromagnetic hysteresis behavior which suggests possible contribution from $\mathrm{Cu}-\mathrm{Fe}-\mathrm{O}$ in addition to that from cubic $\mathrm{CuFe}_{2} \mathrm{O}_{4}$. Neutron diffraction measurements at ambient and at highpressures are necessary on both the $\mathrm{Fe}$-doped $\mathrm{CuO}$ and $\mathrm{Cu}_{2} \mathrm{O}$ samples to shed more light in this aspect.

For the formation of $\mathrm{AB}_{2} \mathrm{O}_{4}$ spinel structure, $\mathrm{A}$ is required to be a dipositive ion, but in $\mathrm{Cu}_{2} \mathrm{O}$, " $\mathrm{Cu}$ " is in +1 oxidation state and hence formation of spinel $\mathrm{CuFe}_{2} \mathrm{O}_{4}$ is not favored. Due to the absence of this spinel impurity phase, "Fe" doped $\mathrm{Cu}_{2} \mathrm{O}$ does not show a dominant ferromagnetic property as it is observed in the case of $1 \% \mathrm{Fe}$-doped $\mathrm{CuO}$.

The coordination number between $\mathrm{Cu}$ and $\mathrm{O}$ atoms in tenorite $\mathrm{CuO}(2+)$ and cuprite $\mathrm{Cu}_{2} \mathrm{O}(1+)$ is believed to play a crucial role in the observed difference in their magnetic properties with "Fe" doping. In monoclinic $\mathrm{CuO}$, the $\mathrm{Cu}$ atoms are coordinated to four coplanar oxygen situated at the corners of an almost rectangular parallelogram [17] with two more distant apical "O" atoms. A distorted octahedron is formed because of large Jahn-teller effect. Depending on the valence state $(1+, 2+$ or $3+)$, a "Fe" ion has up to 5,4 
and " 3 d" electrons with a total spin of $s=2 \frac{1}{2}, s=2$ and $s=1 \frac{1}{2}$, respectively, due to Hund's rule. A Cu ion has a total spin of $1 / 2$ and hence "Fe" ions doped into $\mathrm{CuO}$ have extra moments which are coupled to the lattice of $\mathrm{Cu}$ spins via superexchange. $\mathrm{CuO}$ at $300 \mathrm{~K}$ is paramagnetic and has one unpaired spin due to the $3 \mathrm{~d}^{9}$ electronic configuration. The fraction of $\mathrm{Fe}^{3+}$ ions substituted at the "Cu" sites in $\mathrm{CuO}$ has 5 unpaired electrons, which might also contribute to the observed magnetic property of "Fe"-doped $\mathrm{CuO}$ by forcing the "Fe" magnetic dipoles to align ferromagnetically by interacting with the unpaired spins of the $\mathrm{CuO}$ which is at paramagnetic state at $300 \mathrm{~K}$. Extending the analogy in $\mathrm{CuO}: \mathrm{Mn}$ [22], we suppose that a fraction of "d" electron states are available for hopping between the "Fe" sites and hence mediating ferromagnetism through the Hund's rule coupling. Hence we attribute the observed magnetic behavior of $\mathrm{CuO}$ : $\mathrm{Fe}$ to have a dominant hidden intrinsic nature apart from the segregated $\mathrm{CuFe}_{2} \mathrm{O}_{4}$ phase whereas this is not in the case of $\mathrm{Cu}_{2} \mathrm{O}$, where we have $\mathrm{Cu}^{+}$ ions coordinated linearly to two " $\mathrm{O}$ " ions, due to its $3 \mathrm{~d}^{10}$ configuration. There are no unpaired spins and the spin value is $s=0$. Hence on substituting with $1 \% \mathrm{Fe}$, irrespective of the charge state of " $\mathrm{Fe}$ ", the $\mathrm{Cu}_{2} \mathrm{O}$ matrix could not mediate a ferromagnetic ordering through the substituted "Fe" ions. Hence, the spin configuration of the host matrix into which " $\mathrm{Fe}$ " is doped is also responsible for the observed magnetic behavior.

\section{Conclusion}

The XRD, TEM, and TGA results imply that the observed magnetic properties of "Fe"-doped $\mathrm{CuO}$ have contribution from the impurity phases, the nature of variation of $H_{C}$ and $M_{\max }$ with increasing "Fe\%", and the role of substitutional "Fe" and non-observation of ferromagnetic behavior in " $\mathrm{Fe}$ "-doped $\mathrm{Cu}_{2} \mathrm{O}$ invites exclusive investigation on $\mathrm{CuO}$. Achieving ferromagnetic behavior from a paramagnetic/antiferromagnetic host by creating a spin imbalance seems to be relatively easier and advantageous than achieving it from diamagnetic oxides like $\mathrm{ZnO}, \mathrm{TiO}_{2}$, and so on. The size dependent magnetic properties of " $\mathrm{Fe}$ "-doped $\mathrm{CuO}$ with controlled formation of $\mathrm{CuFe}_{2} \mathrm{O}_{4}$ are another interesting aspect of this material which could be exploited for applications by suitably varying the size of the particles. The above said properties could be exploited for device applications provided if the " $\mathrm{Fe}$ " composition in $\mathrm{CuO}$ and the preparatory method and processing conditions are stabilized so as to result in a good single phase $\mathrm{Cu}-\mathrm{Fe}-\mathrm{O}$ solid solution with intrinsic magnetization and high reproducibility. Variation of $\mathrm{H}_{C}$ in " $\mathrm{Fe}$ "-doped $\mathrm{CuO}$, though $\mathrm{CuFe}_{2} \mathrm{O}_{4}$ phases are present, extends from "soft" magnetic behaviour to "hard" with variation of " $\mathrm{Fe} \%$ " in the samples studied. This wide variation in $H_{C}$ of such a DMS-like composite material could be thought of for fabricating MTJs with low $H_{C^{-}}$"free" layer and high $H_{C^{-}}$"pinned" layer separated by a thin insulating layer. The advantage of MTJ's made up of such all oxide DMS like layers with high $M_{\max }, T_{N}$, and $H_{C}$ over the metallic $\mathrm{Fe} / \mathrm{AlO}_{x} / \mathrm{NiFe}$ and $\mathrm{CoFeB} / \mathrm{AlO}_{x} / \mathrm{CoFeB}$ type of MTJs is that these are less complicated and cheap and will have very good lattice matching and least strain between the "pinned" and "free" layers.

\section{Acknowledgments}

D. Paul Joseph thanks the CSIR, Government of India, for the award of Senior Research Fellowship, 2007 and Dr. R. Justin Joseyphus, NIT, Trichy, for TEM measurements. The authors thank Prof. Dr. A. Narayansamy of their department and Prof. Dr. M. Palanichamy, Department of Chemistry, Anna University, for critical comments and fruitful discussions. R. S. Vennila acknowledges the Air Force Grant No. 212600548 and COMPRES for the financial support to carry out the above research. Also, the author thanks Prof. S. K. Saxena, Florida International University and Dr. H. P. Liermann of HPCAT (Sector 16), APS, Argonne National Laboratory for their help. Use of the HPCAT facility was supported by DOEBES, DOE-NNSA (CDAC), NSF, DOD-TACOM, and the W. M. Keck foundation.

\section{References}

[1] K. Rode, A. Anane, R. Mattana, J. P. Contour, O. Durand, and R. LeBourgeois, "Magnetic semiconductors based on cobalt substituted ZnO," Journal of Applied Physics, vol. 93, no. 10, pp. 7676-7678, 2003.

[2] P. V. Radovanovic and D. R. Gamelin, "High-temperature ferromagnetism in Ni-doped $\mathrm{ZnO}$ aggregates prepared from colloidal diluted magnetic semiconductor quantum dots," Physical Review Letters, vol. 91, no. 15, Article ID 157202, 4 pages, 2003.

[3] D. P. Joseph, G. S. Kumar, and C. Venkateswaran, "Structural, magnetic and optical studies of $\mathrm{Zn}_{0.95} \mathrm{Mn}_{0.05} \mathrm{O}$ DMS," Materials Letters, vol. 59, no. 21, pp. 2720-2724, 2005.

[4] Y. Matsumoto, M. Murakami, T. Shono et al., "Roomtemperature ferromagnetism in transparent transition metaldoped titanium dioxide," Science, vol. 291, no. 5505, pp. 854856, 2001.

[5] S. B. Ogale, R. J. Choudhary, J. P. Buban et al., "High temperature ferromagnetism with a giant magnetic moment in transparent co-doped $\mathrm{SnO}_{2-\delta}$," Physical Review Letters, vol. 91, no. 7, Article ID 077205, 4 pages, 2003.

[6] T. S. Herng, S. P. Lau, S. F. Yu, H. Y. Yang, K. S. Teng, and J. S. Chen, "Enhancement of ferromagnetism and stability in $\mathrm{Cu}-$ doped $\mathrm{ZnO}$ by $\mathrm{N}_{2} \mathrm{O}$ annealing," Journal of Physics: Condensed Matter, vol. 19, Article ID 356214, 2007.

[7] S. Deka and P. A. Joy, "Synthesis and magnetic properties of Mn doped ZnO nanowires," Solid State Communications, vol. 142, no. 4, pp. 190-194, 2007.

[8] H. Ohno, "Making nonmagnetic semiconductors ferromagnetic," Science, vol. 281, no. 5379, pp. 951-956, 1998.

[9] K. Sato and H. Katayama-Yoshida, "Stabilization of ferromagnetic states by electron doping in Fe-, Co- or Ni-doped $\mathrm{ZnO}$," Japanese Journal of Applied Physics, vol. 40, no. 4, pp. L334L336, 2001.

[10] D. P. Joseph, S. Naveenkumar, N. Sivakumar, and C. Venkateswaran, "Synthesis of $\mathrm{Zn}_{0.95} \mathrm{Cr}_{0.05} \mathrm{O}$ DMS by coprecipitation and ceramic methods: structural and magnetization studies," Materials Chemistry and Physics, vol. 97, no. 1, pp. 188-192, 2006. 
[11] T. Fukumura, Y. Yamada, K. Tamura et al., "Magneto-optical spectroscopy of anatase $\mathrm{TiO} 2$ doped with Co," Japanese Journal of Applied Physics, vol. 42, no. 2, pp. L105-L107, 2003.

[12] Ü. Özgür, Ya. I. Alivov, C. Liu et al., "A comprehensive review of $\mathrm{ZnO}$ materials and devices," Journal of Applied Physics, vol. 98, no. 4, Article ID 041301, 103 pages, 2005.

[13] K. Ando, H. Saito, Z. Jin et al., "Magneto-optical properties of $\mathrm{ZnO}$-based diluted magnetic semiconductors," Journal of Applied Physics, vol. 89, no. 11, pp. 7284-7286, 2001.

[14] P. Dal, H. A. Mook, G. Aeppll, S. M. Hayden, and F. Doǧan, "Resonance as a measure of pairing correlations in the highTc superconductor $\mathrm{YBa}_{2} \mathrm{Cu}_{3} \mathrm{O}_{6.6}$ " Nature, vol. 406, no. 6799, pp. 965-968, 2000.

[15] C. L. Carnes and K. J. Klabunde, "The catalytic methanol synthesis over nanoparticle metal oxide catalysts," Journal of Molecular Catalysis A: Chemical, vol. 194, no. 1-2, pp. 227-236, 2003.

[16] M. Frietsch, F. Zudock, J. Goschnick, and M. Bruns, "CuO catalytic membrane as selectivity trimmer for metal oxide gas sensors," Sensors and Actuators B: Chemical, vol. 65, no. 1, pp. 379-381, 2000.

[17] M. G. Smith, R. D. Taylor, M. P. Pasternak, and H. Oesterreicher, "Mössbauer spectroscopy of $\mathrm{CuO}$ and its relevance to high-temperature superconductors," Physical Review B, vol. 42, no. 4, pp. 2188-2192, 1990.

[18] P. Shah and A. Gupta, "Mössbauer study of iron-doped CuO," Physical Review B, vol. 45, no. 1, pp. 483-485, 1992.

[19] S. B. Ogale, P. G. Bilurkar, S. Joshi, and G. Marest, "Ion57 implantation in laser-deposited cupric and cuprous oxide films: Mössbauer spectroscopy and X-ray-diffraction studies," Physical Review B, vol. 50, no. 14, pp. 9743-9751, 1994.

[20] A. Gupta and P. Shah, "Effect of oxygen stoichiometry in CuO," Physical Review B, vol. 50, no. 18, pp. 13706-13709, 1994.

[21] S. J. Stewart, G. F. Goya, G. Punte, and R. C. Mercader, "Phase transformations in Fe-doped cupric oxide," Journal of Physics and Chemistry of Solids, vol. 58, no. 1, pp. 73-77, 1997.

[22] S. G. Yang, T. Li, B. X. Gu et al., "Ferromagnetism in Mndoped CuO," Applied Physics Letters, vol. 83, no. 18, pp. 37463748, 2003.

[23] R. A. Borzi, S. J. Stewart, G. Punte et al., "Effect of ion doping on CuO magnetism," Journal of Applied Physics, vol. 87, no. 9, pp. 4870-4872, 2000.

[24] Y. R. Park, K. J. Kim, S. L. Choi et al., "Ferromagnetism in Fedoped cupric oxide," Physica Status Solidi B, vol. 244, no. 12, pp. 4578-4581, 2007.

[25] M. Ivill, M. E. Overberg, C. R. Abernathy et al., "Properties of Mn-doped $\mathrm{CuO}$ semiconducting thin films grown by pulsedlaser deposition," Solid-State Electronics, vol. 47, no. 12, pp. 2215-2220, 2003.

[26] T. Tanaka, "Optical constants of polycrystalline 3d transition metal. Oxides in the wavelength region 350 to $1200 \mathrm{~nm}$," Japanese Journal of Applied Physics, vol. 18, no. 6, pp. 10431047, 1979.

[27] Y. Ushio, M. Miyayama, and H. Yanagida, "Photoinduced current of $\mathrm{CuO} / \mathrm{ZnO}$ thin-film heterojunction in humid atmosphere," Japanese Journal of Applied Physics, vol. 33, no. 2, pp. 1136-1139, 1994.

[28] D. H. Yoon, J. H. Yu, and G. M. Choi, "CO gas sensing properties of $\mathrm{ZnO}-\mathrm{CuO}$ composite," Sensors and Actuators B, vol. 46, no. 1, pp. 15-23, 1998.

[29] S. N. Kale, S. B. Ogale, S. R. Shinde et al., "Magnetism in cobalt-doped $\mathrm{CuO}$ thin films without and with $\mathrm{Al}, \mathrm{V}$, or $\mathrm{Zn}$ codopants," Applied Physics Letters, vol. 82, no. 13, pp. 21002102, 2003.

[30] D. P. Joseph, T. P. David, S. P. Raja, and C. Venkateswaran, "Phase stabilization and characterization of nanocrystalline Fe-doped $\mathrm{Cu}_{2} \mathrm{O}$," Materials Characterization, vol. 59, no. 8, pp. 1137-1139, 2008.

[31] W. Wang, O. K. Varghese, C. Ruan, M. Paulose, and C. A. Grimes, "Synthesis of $\mathrm{CuO}$ and $\mathrm{Cu}_{2} \mathrm{O}$ crystalline nanowires using $\mathrm{Cu}(\mathrm{OH})_{2}$ nanowire templates," Journal of Materials Research, vol. 18, no. 12, pp. 2756-2759, 2003.

[32] L. Lutterotti, "MAUD materials analysis using diffraction version:1.84," 2002, http://www.ing.unitn.it/ maud/.

[33] N. C. Holmes, J. A. Moriarty, G. R. Gathers, and W. J. Nellis, "The equation of state of platinum to $660 \mathrm{GPa}$ (6.6 Mbar)," Journal of Applied Physics, vol. 66, no. 7, pp. 2962-2967, 1989.

[34] A. C. Larson and R. B. von Dreele, "General Structure Analysis System (GSAS)," National Laboratory Report LAUR 86-748, 2004.

[35] B. H. Toby, "EXPGUI, a graphical user interface for GSAS," Journal of Applied Crystallography, vol. 34, no. 2, pp. 210-213, 2001.

[36] L. C. Bourne, P. Y. Yu, A. Zettl, and M. L. Cohen, "Highpressure electrical conductivity measurements in the copper oxides," Physical Review B, vol. 40, no. 16, pp. 10973-10976, 1989.

[37] A. Malinowski, S. Asbrink, and A. Kvick, "A high-pressure single-crystal X-ray diffraction study of copper oxide using synchrotron radiation," High Pressure Research, vol. 4, no. 1, pp. 429-431, 1990.

[38] H. Ehrenberg, J. A. McAllister, W. G. Marshall, and J. P. Attfield, "Compressibility of copper-oxygen bonds: a highpressure neutron powder diffraction study of CuO," Journal of Physics Condensed Matter, vol. 11, no. 34, pp. 6501-6508, 1999.

[39] Z. Wang, V. Pischedda, S. K. Saxena, and P. Lazor, "X-ray diffraction and Raman spectroscopic study of nanocrystalline $\mathrm{CuO}$ under pressures," Solid State Communications, vol. 121, no. 5, pp. 275-279, 2002.

[40] S. Minomura and H. G. Drickamer, "Effect of pressure on the electrical resistance of some transition-metal oxides and sulfides," Journal of Applied Physics, vol. 34, no. 10, pp. 30433048, 1963.

[41] K. Reimann and K. Syassen, "Pressure dependence of Raman modes in CuO," Solid State Communications, vol. 76, no. 2, pp. 137-140, 1990.

[42] E. C. Stoner and E. P. Wohlfarth, "A mechanism of magnetic hysteresis in heterogeneous alloys," Philosophical Transactions of the Royal Society A, vol. 240, pp. 599-642, 1948.

[43] B. D. Cullity, Introduction to Magnetic Materials, AddisonWesley, Philippines, Pa, USA, 1972.

[44] A. P. Douvalis, L. Jankovic, and T. Bakas, "The origin of ferromagnetism in ${ }^{57} \mathrm{Fe}$-doped NiO," Journal of Physics Condensed Matter, vol. 19, no. 43, Article ID 436203, 2007.

[45] A. Punnoose, H. Magnone, M. S. Seehra, and J. Bonevich, "Bulk to nanoscale magnetism and exchange bias in $\mathrm{CuO}$ nanoparticles," Physical Review B, vol. 64, no. 17, Article ID 174420, 8 pages, 2001.

[46] W. H. Meiklejohn and C. P. Bean, "New magnetic anisotropy," Physical Review, vol. 105, no. 3, pp. 904-913, 1957.

[47] T. I. Arbuzova, A. A. Samokhvalov, I. B. Smolyak, B. V. Karpenko, N. M. Chebotaev, and S. V. Naumov, "Temperature transition from $3 \mathrm{D}$ to quasi-1D antiferromagnetism in $\mathrm{CuO}$ 
single crystals," Journal of Magnetism and Magnetic Materials, vol. 95, no. 2, pp. 168-174, 1991.

[48] S. Cardoso, Z. Zhang, H. Li et al., "Characterization of nano-oxide layers fabricated by ion beam oxidation," IEEE Transactions on Magnetics, vol. 38, no. 5, pp. 2755-2757, 2002.

[49] H. Toyosaki, T. Fukumura, K. Ueno, M. Nakano, and M. Kawasaki, "A ferromagnetic oxide semiconductor as spin injection electrode in magnetic tunnel junction," Japanese Journal of Applied Physics, vol. 44, no. 28, pp. L896-L898, 2005.

[50] X. W. Li, A. Gupta, G. Xiao, W. Qian, and V. P. Dravid, "Fabrication and properties of heteroepitaxial magnetite $(\mathrm{FeO})$ tunnel junctions," Applied Physics Letters, vol. 73, no. 22, pp. 3282-3284, 1998.

[51] P. A. A. van der Heijden, P. J. H. Bloemen, J. M. Metselaar et al., "Interlayer coupling between FeO layers separated by an insulating nonmagnetic MgO layer," Physical Review B, vol. 55, no. 17, pp. 11569-11575, 1997.

[52] P. J. van der Zaag, P. J. H. Bloemen, J. M. Gaines et al., "On the construction of an $\mathrm{Fe}_{3} \mathrm{O}_{4}$-based all-oxide spin valve," Journal of Magnetism and Magnetic Materials, vol. 211, no. 1, pp. 301$308,2000$.

[53] G. Hu, R. Chopdekar, and Y. Suzuki, “Observation of inverse magnetoresistance in epitaxial magnetite/manganite junctions," Journal of Applied Physics, vol. 93, no. 10, pp. 75167518, 2003.

[54] L. M. B. Alldredge, R. V. Chopdekar, B. B. Nelson-Cheeseman, and Y. Suzuki, "Complex oxide-based magnetic tunnel junctions with nonmagnetic insulating barrier layers," Journal of Applied Physics, vol. 99, no. 8, Article ID 08K303, 2006.

[55] T. Fix, D. Stoeffler, Y. Henry et al., "Diode effect in alloxide $\mathrm{Sr}_{2} \mathrm{FeMoO}_{6}$-based magnetic tunnel junctions," Journal of Applied Physics, vol. 99, no. 8, Article ID 08J107, 2006.

[56] G. Bertotti, Hysteresis in Magnetism, chapter 10, 11, Academic Press, New York, NY, USA, 1998.

[57] V. Raghavan, Materials Science and Engineering, Prentice-Hall, New Delhi, India, 3rd edition, 1995. 

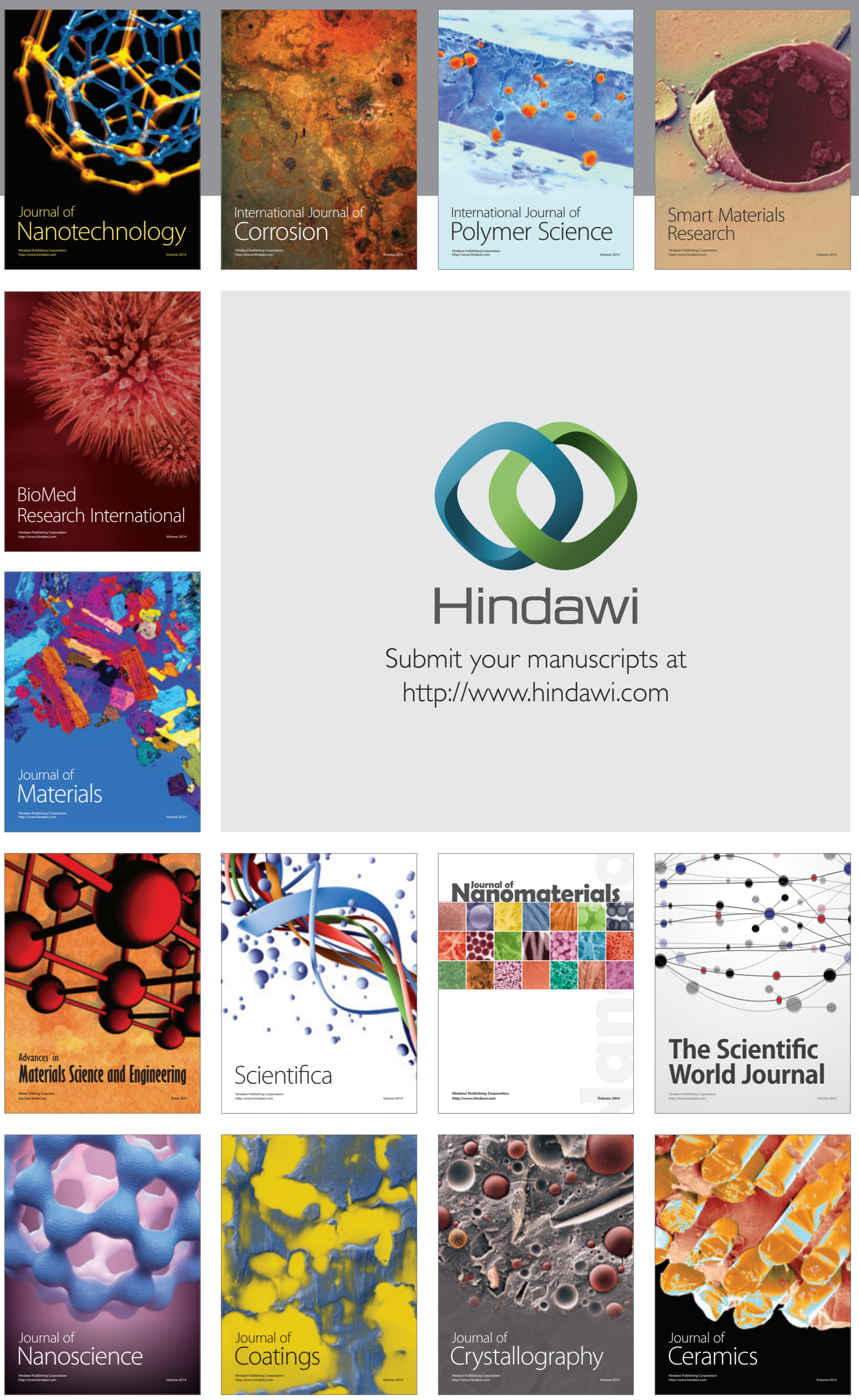

The Scientific World Journal

Submit your manuscripts at

http://www.hindawi.com

\section{World Journal}

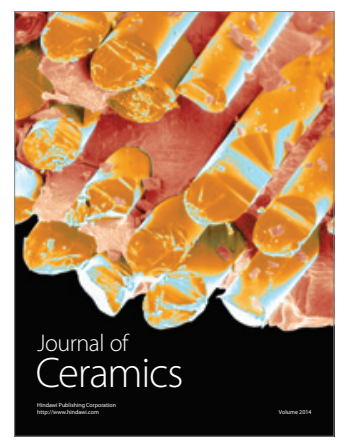

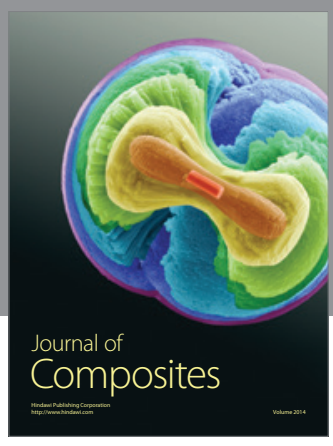
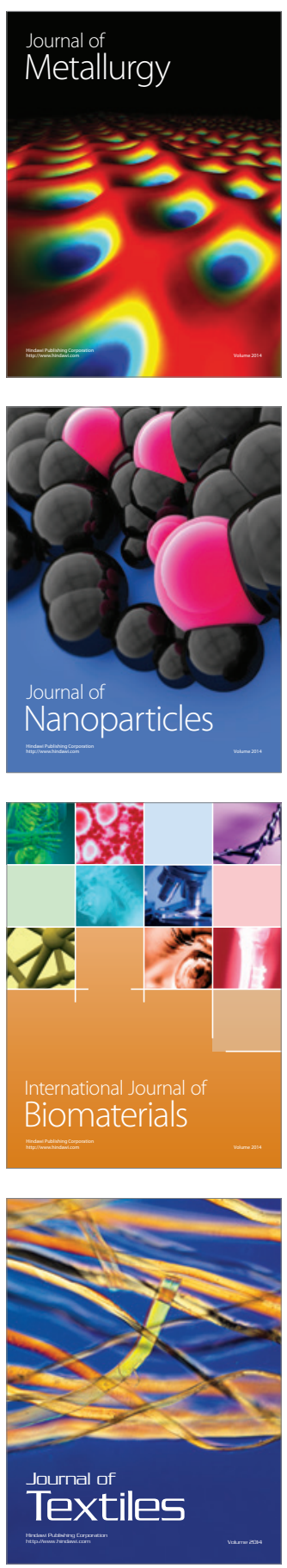